\title{
Impact of Model Resolution on the Simulation of Precipitation Extremes over China
}

\author{
Neng Luo (1) and Yan Guo * \\ State Key Laboratory of Earth Surface Processes and Resource Ecology, Faculty of Geographical Science, \\ Beijing Normal University, Beijing 100875, China; luoneng@mail.bnu.edu.cn \\ * Correspondence: guoyan@bnu.edu.cn
}

check for

updates

Citation: Luo, N.; Guo, Y. Impact of Model Resolution on the Simulation of Precipitation Extremes over China. Sustainability 2022, 14, 25. https:// doi.org/10.3390/su14010025

Academic Editor: Ozgur Kisi

Received: 1 December 2021

Accepted: 19 December 2021

Published: 21 December 2021

Publisher's Note: MDPI stays neutral with regard to jurisdictional claims in published maps and institutional affiliations.

Copyright: (C) 2021 by the authors. Licensee MDPI, Basel, Switzerland. This article is an open access article distributed under the terms and conditions of the Creative Commons Attribution (CC BY) license (https:// creativecommons.org/licenses/by/ $4.0 /)$.

\begin{abstract}
Climate models tend to overestimate light precipitation and underestimate heavy precipitation due to low model resolution. This work investigated the impact of model resolution on simulating the precipitation extremes over China during 1995-2014, based on five models from Coupled Model Intercomparison Project 6 (CMIP6), each having low- and high-resolution versions. Six extreme indices were employed: simple daily intensity index (SDII), wet days (WD), total precipitation (PRCPTOT), extreme precipitation amount (R95p), heavy precipitation days (R20mm), and consecutive dry days (CDD). Models with high resolution demonstrated better performance in reproducing the pattern of climatological precipitation extremes over China, especially in the western Sichuan Basin along the eastern side of the Tibetan Plateau (D1), South China (D2), and the Yangtze-Yellow River basins (D3). Decreased biases of precipitation exist in all high-resolution models over D1, with the largest decease in root mean square error (RMSE) being 48.4\% in CNRM-CM6. The improvement could be attributed to fewer weak precipitation events $(0 \mathrm{~mm} /$ day $-10 \mathrm{~mm} /$ day $)$ in high-resolution models in comparison with their counterparts with low resolutions. In addition, high-resolution models also show smaller biases over D2, which is associated with better capturing of the distribution of daily precipitation frequency and improvement of the simulation of the vertical distribution of moisture content.
\end{abstract}

Keywords: precipitation; China; CMIP6; model resolutions

\section{Introduction}

Increased climate extremes in terms of frequency and intensity, such as extreme precipitation events, have been observed in the context of global warming, which have immensely adverse impacts on economic production and human life. The simulation in precipitation extremes over complex terrain is challenging but crucial for investing the performance of models. For example, the Pacific Northwest of the United States is characterized by complex topography, including land-sea contrasts and mountains ranges, which is challenging for global models [1]. China is strongly affected by precipitation extremes due to complex terrain, vast areas, and the influence of the topographically complex Tibetan Plateau and East Asian monsoon system. Many extreme precipitation events have been reported in China. On 6-7 May 2017, the coastal city of Guangzhou experienced severe extreme precipitation with maximum rainfall above $500 \mathrm{~mm}$ in one day, eventually causing enormous economic losses [2]. Severe flooding occurred in the Yangtze River in 2020 and caused at least 141 deaths, with direct economic losses of 82.23 billion yuan by 12 July 2020 [3]. On 20 July 2021, Zhengzhou experienced a recordbreaking torrential rainfall of above $200 \mathrm{~mm}$ within one hour, eventually causing direct economic losses amounting to 53.2 billion yuan [4]. Therefore, the best way to improve the ability of climate models to simulate or project precipitation extremes has received a lot of attention from the climate community.

Previous studies have demonstrated the advantage of high-resolution simulation, including improvements in large-scale atmospheric and oceanic circulation $[5,6]$, tropical 
cyclones [7,8], El Niño-Southern Oscillation [9], and precipitation [10-12]. For example, the authors of [13] found that high-resolution models obtain better performance in simulating the frequency and percentage of extreme precipitation in eastern China. Using two atmospheric general circulation models from the UK Met Office Hadley Centre, the authors of [14] demonstrated that the model resolution has an effect on the hydrological cycle by increasing (decreasing) precipitation over land (ocean), eventually making highresolution simulations closer to observations over the ocean but further away over land. The authors of [15] indicated that a model with a horizontal grid spacing less than $4 \mathrm{~km}$ (convection-permitting model), better representing orography and variations in surface fields, can improve precipitation simulation in mountainous regions. The authors of [16] indicated that models in higher resolution better simulate the precipitation extremes in the mountainous regions over northern China and Sichuan but that their skill in simulating precipitation over the Maritime Continent is low.

Currently, the World Climate Research Programme (WCRP) launched the latest Coupled Model Intercomparison Project (CMIP6), which aimed to answer new scientific questions in the field of climate change and provided data available to achieve the scientific goal set by the WCRP. Most CMIP6 models have updated parameterization schemes and higher resolutions compared with CMIP5 models [17]. Studies have demonstrated that CMIP6 models generally help simulate the mean and extreme precipitation compared with CMIP5 models [18-22]. For example, the authors of [23] evaluated the performance of six CMIP6 and CMIP5 models in simulating extreme precipitation in China and indicated that heavy precipitation events ( $>20 \mathrm{~mm} /$ day) over southern China are well captured by CMIP6 models, which might be related to model resolutions and precipitation-related parameterization schemes. The authors of [24] indicated that the southeast-northwest gradient of rainfall over China is underestimated in CMIP6 models but less than that in CMIP5 models, which is possibly associated with model resolution. The authors of [25] assessed the performance of 18 CMIP6 models participating in the High-Resolution Model Inter-comparison Project (HighResMIP) in simulating the climatological precipitation over China and indicated that models in higher resolution show better skill in simulating the spatial distribution, and the precipitation bias over the Tibetan Plateau, northern China, and southern China has been obviously reduced.

Several factors, such as physical parameterization, affect the model simulation of precipitation extremes besides model resolution. Thus, the impact of model resolution should be investigated using identical models, which only differ with respect to resolution. Based on five state-of-the-art CMIP6 models, with each having a pair of high-resolution and low-resolution configurations, we aim to study the impact of model resolution on their fidelity in simulating the precipitation extremes over China in this study. We used five CMIP6 models, with each having high-resolution and low-resolution configurations. We found that models with improved resolutions show common improvements in the simulation of precipitation extremes in China compared with their counterparts with low resolutions. In addition, the vertical distribution of moisture content is better represented in high-resolution models. Our results indicate high-resolution models are crucial for improving projection in precipitation extremes events.

\section{Materials and Methods}

\subsection{Observational and Model Data}

The gridded observational precipitation data were from CN05.1 on a $0.25 \times 0.25$ grid reference [26]. The dataset was produced by the National Climate Center of the China Meteorological Administration from over 2400 observation stations over China. The reliability of this dataset has been proven in previous studies $[27,28]$. Relative humidity data were from ERA5 reanalysis dataset in horizontal resolution of $0.25^{\circ} \times 0.25^{\circ}$ [29].

In this study, five CMIP6 models, each having high-resolution and low-resolution configurations (totally ten models), were obtained from data portals of the Earth System Grid Federation (https: / / esgf-node.llnl.gov/projects/esgf-1lnl/, accessed on 31 August 
2021). Detailed information about the ten models is provided in Table 1. Only the first realization was used for each model. To achieve a convenient comparison, all model outputs were re-gridded into $1^{\circ} \times 1^{\circ}$ grid using the bilinear interpolation method. The period of 1995-2014 was chosen as the climatology to perform evaluation.

Table 1. CMIP6 models used in the study.

\begin{tabular}{ccccc}
\hline Institute & High & Resolution & Low & Resolution \\
\hline $\begin{array}{c}\text { National Centre for } \\
\text { Meteorological Research, France }\end{array}$ & CNRM-CM6-1-HR & $0.5^{\circ} \times 0.5^{\circ}$ & CNRM-CM6-1 & $1.4^{\circ} \times 1.4^{\circ}$ \\
\hline EC-Earth consortium & EC-Earth3-Veg & $0.7^{\circ} \times 0.7^{\circ}$ & EC-Earth3-Veg-LR & $1.125^{\circ} \times 1.25^{\circ}$ \\
\hline Met Office Hadley Centre, UK & HadGEM3-GC31-MM & $0.556^{\circ} \times 0.833^{\circ}$ & HadGEM3-GC31-LL $^{\circ} 1.25^{\circ} \times 1.875^{\circ}$ \\
\hline $\begin{array}{c}\text { Max Planck Institute for } \\
\text { Meteorology, Germany }\end{array}$ & MPI-ESM1-2-HR & $0.94^{\circ} \times 0.94^{\circ}$ & MPI-ESM1-2-LR & $1.9^{\circ} \times 1.9^{\circ}$ \\
\hline $\begin{array}{c}\text { NorESM Climate modelling } \\
\text { Consortium consisting } \\
\text { of CICERO }\end{array}$ & NorESM2-MM & $0.94^{\circ} \times 1.25^{\circ}$ & NorESM2-LM & $1.9^{\circ} \times 2.5^{\circ}$ \\
\hline
\end{tabular}

\subsection{Methods}

Six precipitation extreme indices were employed (Table 2): simple daily intensity index (SDII), wet days (WD), total precipitation (PRCPTOT), extreme precipitation amount (R95p), heavy precipitation days (R20mm), and consecutive dry days (CDD). These indices have been commonly used in previous studies [30,31].

Table 2. Definitions of precipitation indices used in this study. RR is daily precipitation.

\begin{tabular}{ccc}
\hline Label & Index Definition & Units \\
\hline PRCPTOT & Annual total precipitation on wet days (RR $\geq 1 \mathrm{~mm})$ & $\mathrm{mm}$ \\
WD & Annual mean count of wet days (RR $\geq 1 \mathrm{~mm})$ & days \\
SDII & Mean precipitation on wet days (RR $\geq 1 \mathrm{~mm})$ & $\mathrm{mm} /$ day \\
CDD & Annual count of maximum number of consecutive dry days $(\mathrm{RR}<1 \mathrm{~mm})$ & days \\
R95p & Accumulated precipitation amounts when RR $>95$ th percentile & mm \\
R20mm & Annual count of days when RR $\geq 20 \mathrm{~mm}$ & days \\
\hline
\end{tabular}

Taylor diagrams are commonly used to evaluate two spatial patterns and to provide a pathway of how well the simulation matches the observation in terms of the standard deviation, correlation coefficient, and root mean square error (RMSE) [32].

\section{Results}

\subsection{Comparison between Models in High-Resolution and Low-Resolution}

The spatial pattern of model biases in climatological PRCPTOT over China from five individual models and their ensemble mean (MME) are shown in Figure 1. Compared with models in low resolution, high-resolution models show obvious improvement over southern China. To facilitate quantitative description of these improvements, three regions were determined as follows: western Sichuan Basin along the east side of the Tibetan Plateau (D1), South China (D2), and the Yangtze-Yellow River basins (D3) (black boxes in Figure 1). The common wet biases over D1 are reduced, with RMSE decreased by $48.4 \%$ in CNRM-CM6, 11.5\% in EC-Earth3, 34.1\% in HadGEM3, 32.1\% in MPI-ESM1, 18.0\% in NorESM2, and 34.3\% in MME, respectively. This improvement has also been shown in previous studies $[33,34]$, and it has been attributed to better representing of complex terrain [35]. Most models present decreased biases over D2, with RMSE reductions reaching $29.9 \%, 24.0 \%, 25.4 \%, 27.2 \%$, and 26.8\% in CNRM-CM6, EC-Earth3, HadGEM3, NorESM2, and MME, respectively. However, it should be noted that the high-resolution model is not 
implicitly perfect, such as MPI-ESM1, with RMSE increasing by $17.7 \%$ over D2 compared with the low-resolution versions. In addition, the biases over D3 are also reduced in the high-resolution models compared with the low-resolution models, with the largest reduction in bias existing in HadGEM3 at a magnitude exceeding 52.2\%.
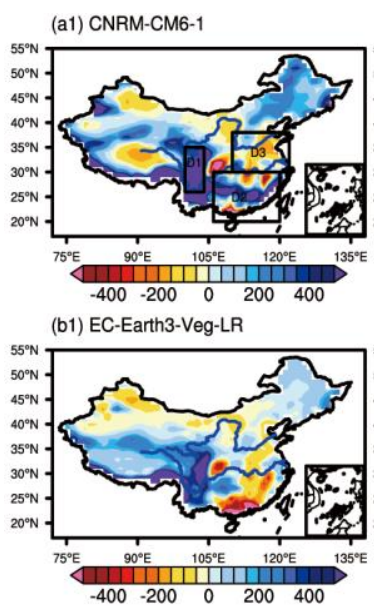

(c1) HadGEM3-GC31-LL

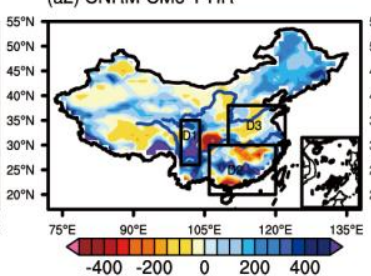

(b2) EC-Earth3-Veg

(a3) High-Low

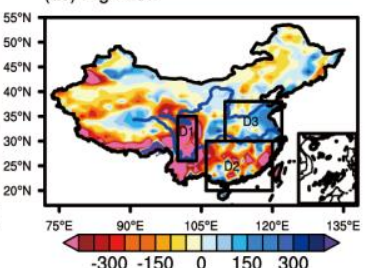

(b3) High-Low
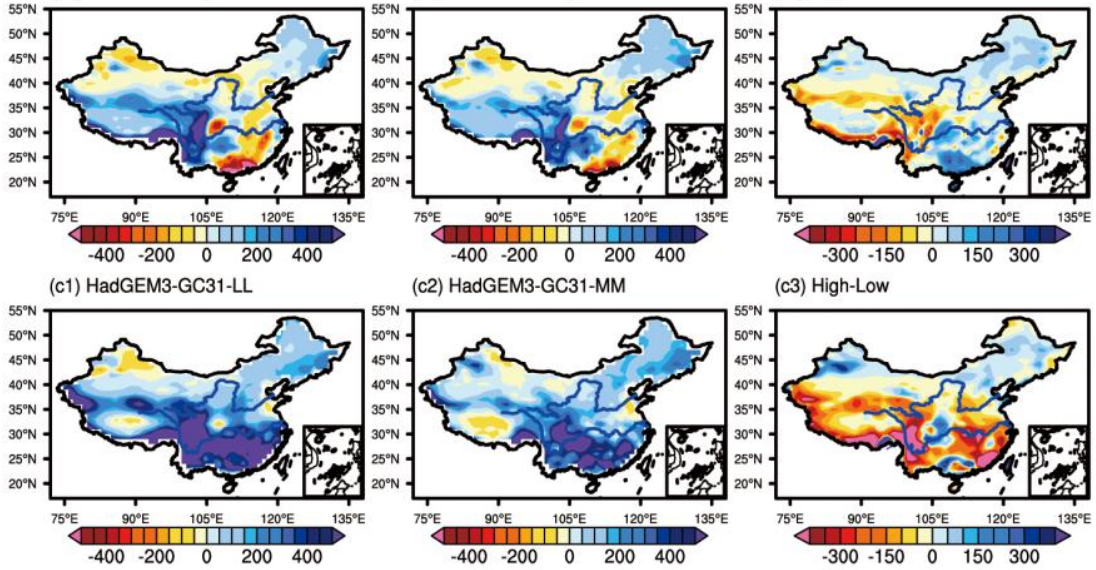

(c2) HadGEM3-GC31-MM

(c3) High-Low
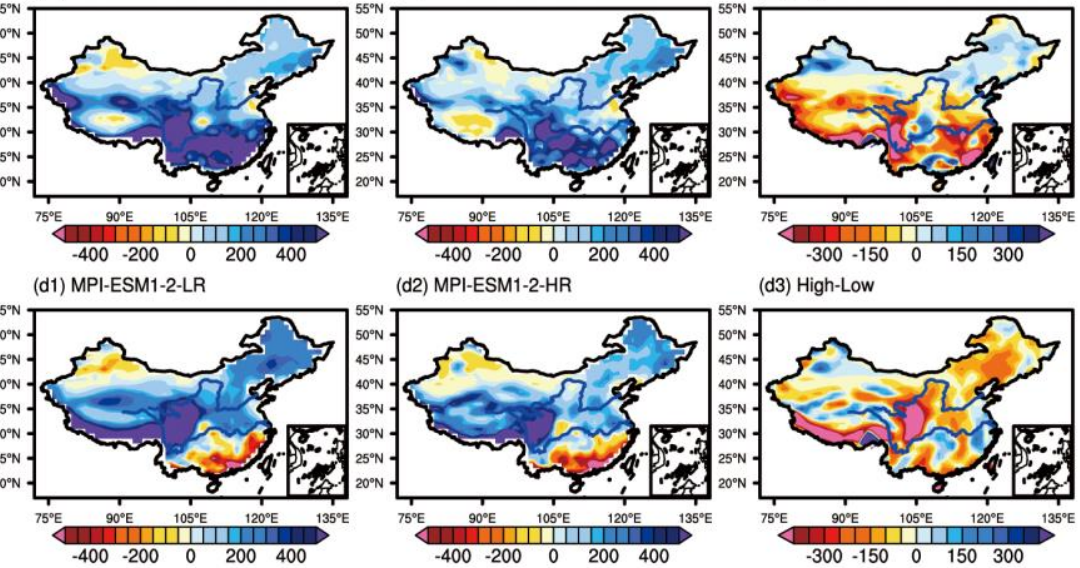

(d3) High-Low
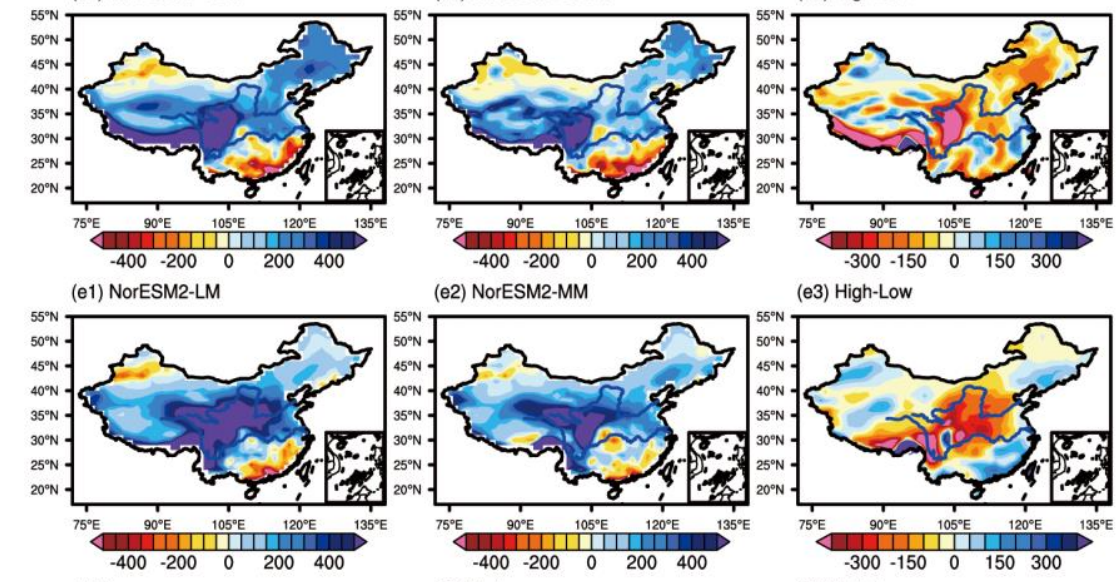

(e3) High-Low
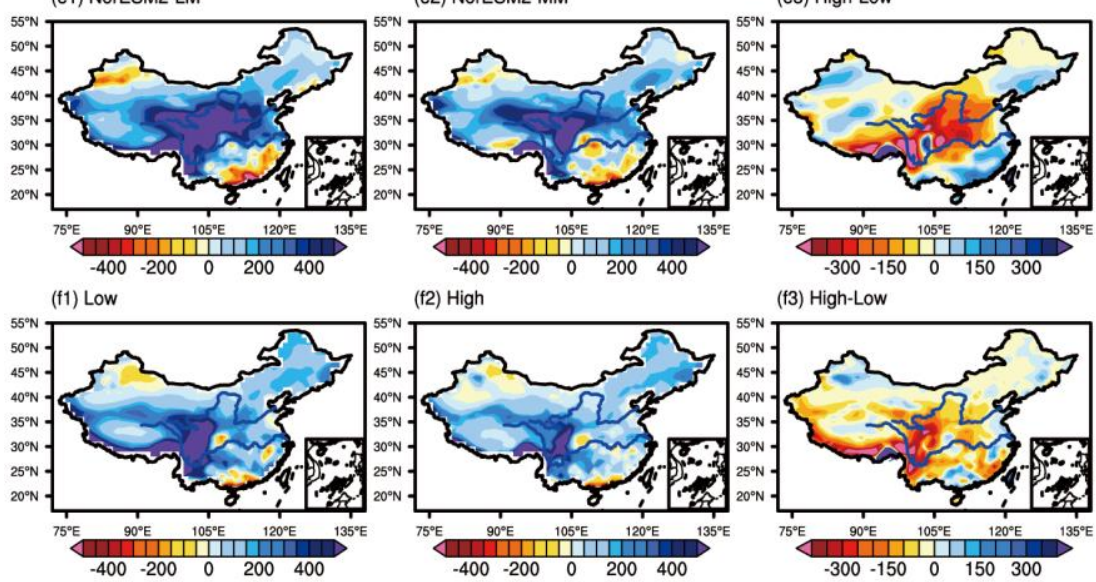

( $\$ 3)$ High-Low

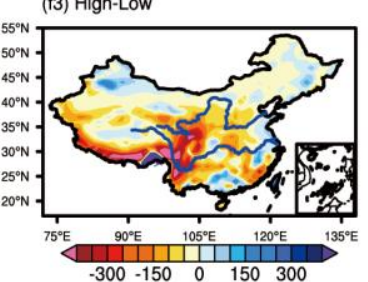

Figure 1. The spatial patterns of biases (departures from CN05.1) in PRCPTOT (unit: mm) for long-term mean (1995-2014) from low-resolution (first column) and high-resolution (second column) models, and differences between low-resolution and high-resolution models (third column). The last row shows multimodels with low-resolution ensemble means (f1) and multimodels with highresolution ensemble means (f2), respectively. 
The spatial pattern of model bias in WD index over China is shown in Figure 2. The biases over D1 are obviously lower in the high-resolution models, with RMSE reductions reaching $12.5 \%, 15.1 \%, 32.8 \%, 54.3 \%, 31.4 \%$, and $42.2 \%$ in CNRM-CM6, EC-Earth3, HadGEM3, NorESM2, and MME, respectively. In addition, the biases over D2 and D3 in most models, with improved resolutions, are also lower. For example, biases over D2 (D3) in MPI-ESM1 are reduced by $20.4 \%$ (50.0\%).
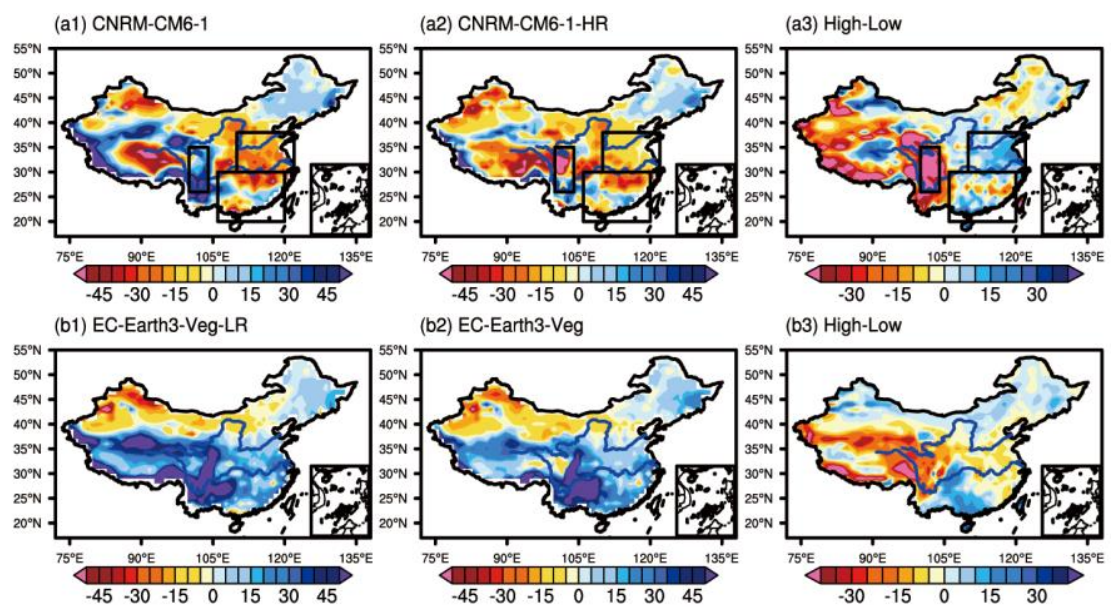
(b2) EC-Earth3-Veg

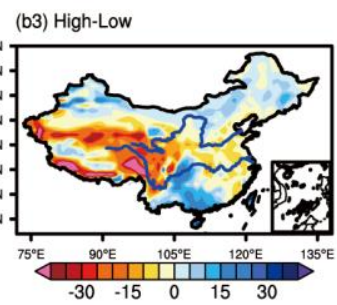

(c1) HadGEM3-GC31-LL

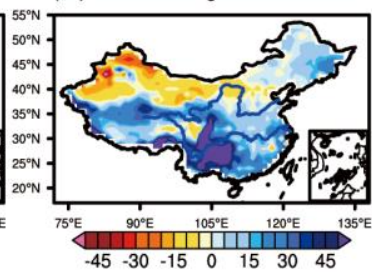

(c2) HadGEM3-GC31-MM

(c3) High-Low
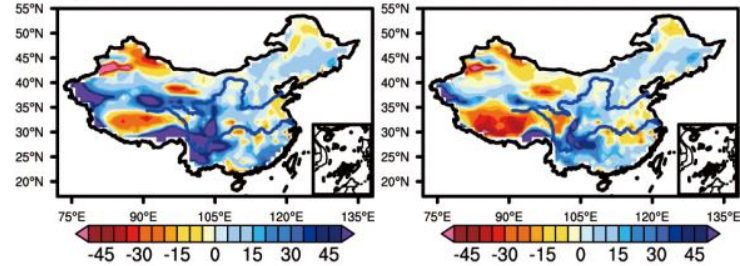

(d1) MPI-ESM1-2-LR

(d2) MPI-ESM1-2-HR
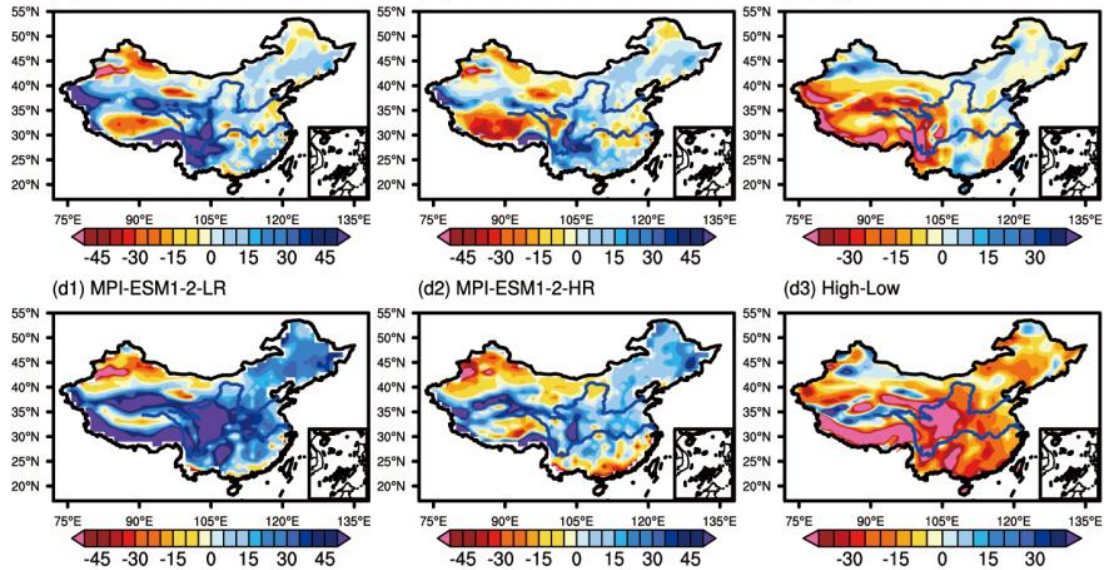

(d3) High-Low

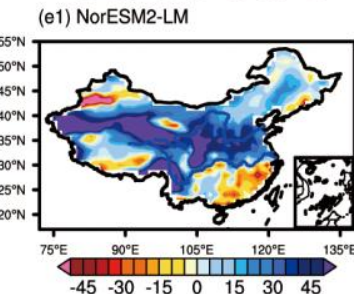
(e2) NorESM2-MM
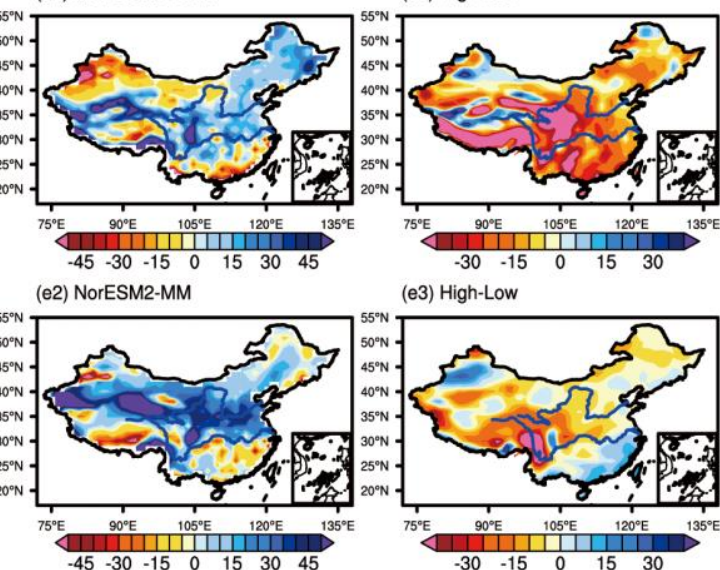

(e3) High-Low

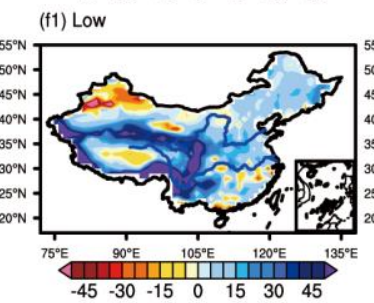
(f2) High
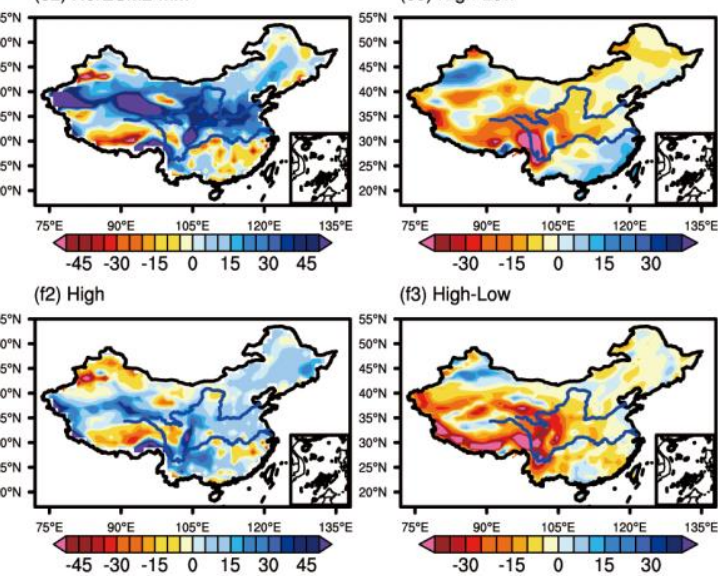

(f3) High-Low

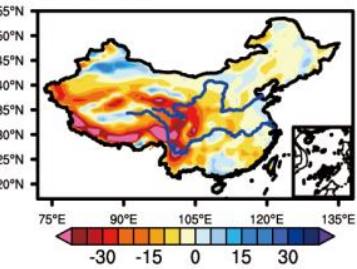

Figure 2. The spatial patterns of biases (departures from CN05.1) in WD (unit: days) for long-term mean (1995-2014) from low-resolution (first column) and high-resolution (second column) models, and differences between low-resolution and high-resolution models (third column). The last row shows multimodels with low-resolution ensemble means (f1) and multimodels with high-resolution ensemble means (f2), respectively. 
The spatial pattern of model biases in representing the SDII over China are shown in Figure 3. The biases over D2 and D3 are remarkably lower in nearly all models with high resolutions, in comparison with low resolution models. For example, the RMSE decreased by $30.7 \%$ (22.1\%) in CNRM-CM6, $14.6 \%$ (21.1\%) in EC-Earth3, 19.7\% (37.3\%) in HadGEM3, 36.6\% (20.1\%) in MPI-ESM1, and 10.8\% (18.9\%) in MME. Regional averaged biases in PRCPTOT, WD, and SDII over D1, D2, and D3 from the individual models and MME are shown in Table 3. The reduction in wet biases over D1 in CNRM-CM6, HadGEM3, NorESM2, and MME could be due to the decreased precipitation frequency and the weakened precipitation intensity. However, for EC-Earth3 and MPI-ESM1, the contribution of precipitation frequency reduction is dominant. The reduction in biases over D2 in NorESM2 is associated with precipitation frequency. In EC-Earth3, HadGEM3, and $\mathrm{MME}$, the reduction biases over $\mathrm{D} 2$ is related to precipitation frequency and precipitation intensity. In addition, the decreased biases over D3 in CNRM-CM6 and MPI-ESM1 could result from precipitation frequency. In HadGEM3, NorESM2, and MME, the decreased biases could be associated with precipitation frequency and precipitation intensity.

Table 3. The area-weighted average biases (departures from CN05.1) and differences between highresolution and low-resolution models in PRCPTOT (unit: $\mathrm{mm}$ ), WD (unit: days), and SDII (unit: $\mathrm{mm}$ /day) over D1, D2, and D3 from individual model, multimodels with low-resolution ensemble means, and multimodels with high-resolution ensemble means.

\begin{tabular}{|c|c|c|c|c|c|c|c|c|c|}
\hline \multirow{2}{*}{ Model } & \multicolumn{3}{|c|}{ D1 } & \multicolumn{3}{|c|}{ D2 } & \multicolumn{3}{|c|}{ D3 } \\
\hline & PRCPTOT & WD & SDII & PRCPTOT & WD & SDII & PRCPTOT & WD & SDII \\
\hline CNRM-CM6-1-HR & +292.7 & -15.6 & +2.3 & +53.1 & -8.9 & +0.8 & +17.1 & -11.7 & +1.4 \\
\hline CNRM-CM6-1 & +814.0 & +31.6 & +3.1 & +159.4 & -11.0 & +1.7 & -38.2 & -19.5 & +1.8 \\
\hline High-Low & -521.3 & -47.2 & -0.8 & -106.3 & +2.1 & -0.9 & +55.3 & +7.8 & -0.4 \\
\hline EC-Earth3-Veg & +351.7 & +31.9 & +0.75 & -47.1 & +25.4 & -1.7 & -6.0 & +9.8 & -1.0 \\
\hline EC-Earth3-Veg-LR & +433.7 & +46.9 & +0.65 & -145.7 & +20.2 & -2.0 & -4.2 & +14.3 & -1.3 \\
\hline High-Low & -82.0 & -15 & +0.1 & +98.6 & +5.2 & +0.3 & -1.8 & -4.5 & +0.3 \\
\hline HadGEM3-GC31-MM & +406.0 & +14.9 & +1.8 & +383.6 & +5.9 & +2.0 & +77.2 & -0.9 & +0.9 \\
\hline HadGEM3-GC31-LL & +667.6 & +40.6 & +2.1 & +532.8 & +8.8 & +2.7 & +191.9 & +2.0 & +1.7 \\
\hline High-Low & -261.6 & -25.7 & -0.3 & -149.2 & -2.9 & -0.7 & -114.7 & -2.9 & -0.8 \\
\hline MPI-ESM1-2-HR & +520.1 & +14.5 & +2.5 & -220.4 & -6.6 & -1.0 & +113.9 & +9.5 & +0.2 \\
\hline MPI-ESM1-2-LR & +798.5 & +55.3 & +2.1 & -186.0 & +17.8 & -2.1 & +151.2 & +24.4 & -0.6 \\
\hline High-Low & -278.4 & -40.8 & +0.4 & -34.4 & -24.4 & +1.1 & -37.3 & -14.9 & +0.8 \\
\hline NorESM2-MM & +520.7 & +16.5 & +2.4 & -60.6 & -4.4 & -0.1 & +192.1 & +24.2 & -0.4 \\
\hline NorESM2-LM & +685.4 & +34.0 & +2.5 & -85.7 & -8.1 & -0.02 & +321.8 & +27.4 & +0.5 \\
\hline High-Low & -164.7 & -17.5 & -0.1 & +25.1 & +3.7 & -0.08 & -129.7 & -3.2 & -0.9 \\
\hline High & +418.2 & +12.4 & +1.9 & +21.7 & +2.2 & +0.01 & +78.9 & +6.2 & +0.2 \\
\hline Low & +679.8 & +41.7 & +2.1 & +55.0 & +5.5 & +0.07 & +124.5 & +9.7 & +0.4 \\
\hline High-Low & -261.6 & -29.3 & -0.2 & -33.3 & -3.3 & -0.06 & -45.6 & -3.5 & -0.2 \\
\hline
\end{tabular}

Simulation for the climatological extreme indices, R95p, R20mm, and CDD, were evaluated. In observation, the pattern of R95p and R20mm (Figures S1 and S2) shows a transition from small values in northwestern China to large values in southeastern China, consistent with the total precipitation (PRCPTOT) (Figure S3). The pattern of CDD shows an opposite distribution (Figure S4), which has been indicated in previous studies [36,37].

Figure 4 shows the spatial patterns of model biases in R95p over China. The biases in the high-resolution models over D2 (D3) are significantly reduced compared with those in 
the low-resolution models, with the reduction in RMSE reaching $22.8 \%(30.7 \%)$ in CNRMCM6, $11.2 \%$ (15.6\%) in HadGEM3, 31.2\% (29.3\%) in NorESM2, and 26.9\% (6.6\%) in MME. For the simulation over D1, obvious decreasing biases are found in CNRM-CM6, MPI-ESM1, and MME, with RMSE reductions of approximately $45.8 \%, 29.6 \%$, and $26.8 \%$, respectively.
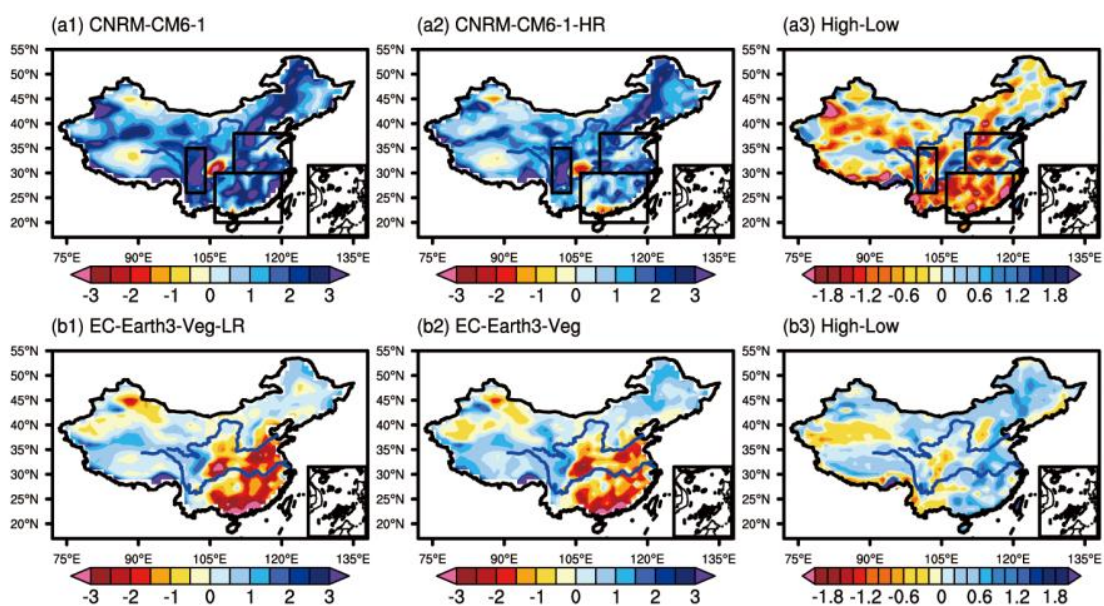

(b2) EC-Earth3-Veg

(b3) High-Low
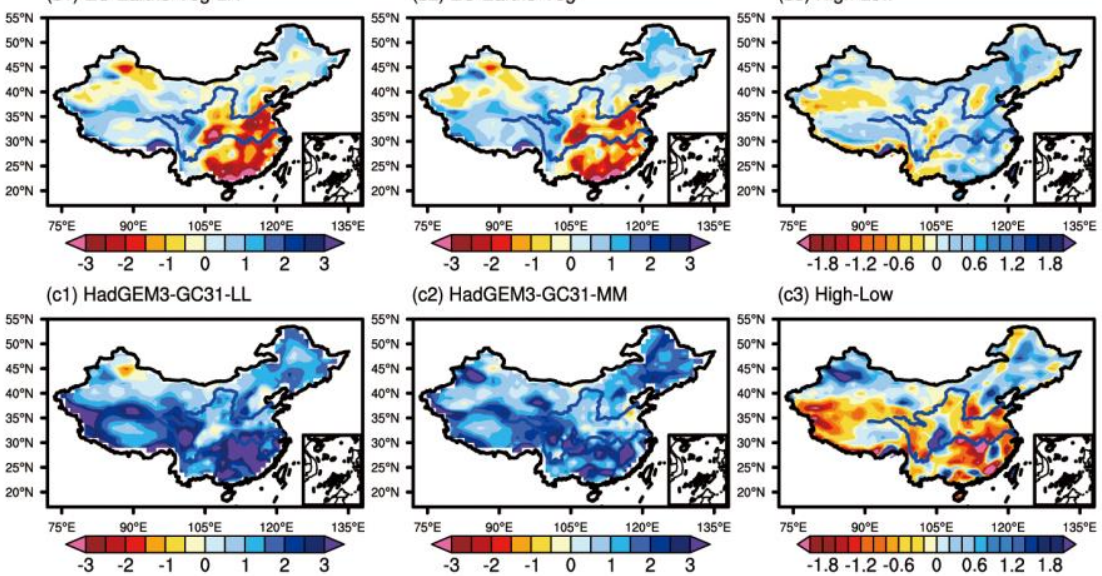

(c2) HadGEM3-GC31-MM (c3) High-Low
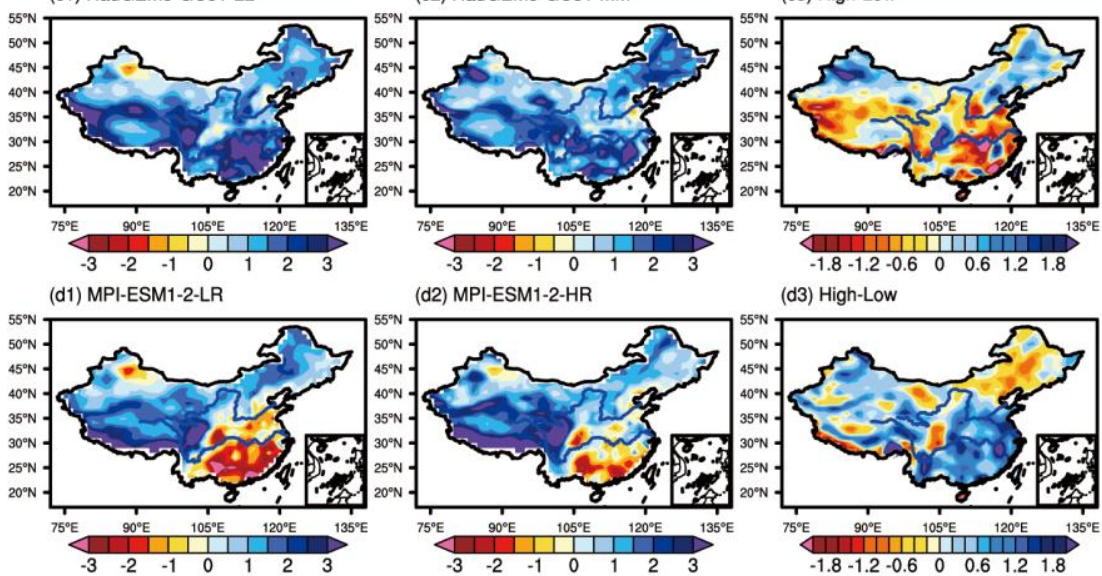

(d2) MPI-ESM1-2-HR

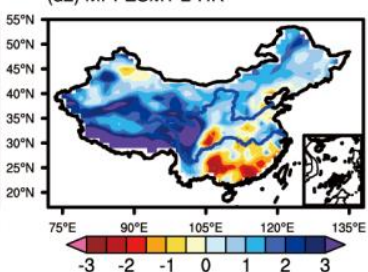

(d3) High-Low

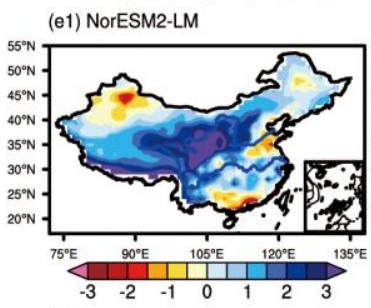

(e2) NorESM2-MM
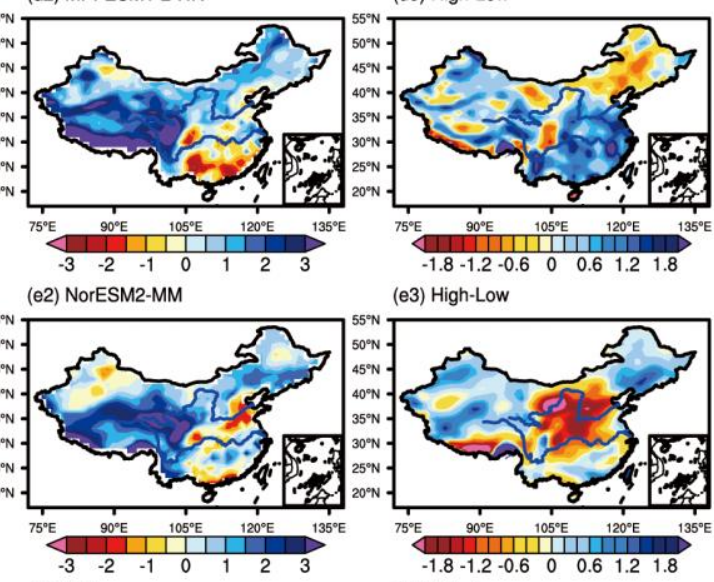

(e3) High-Low
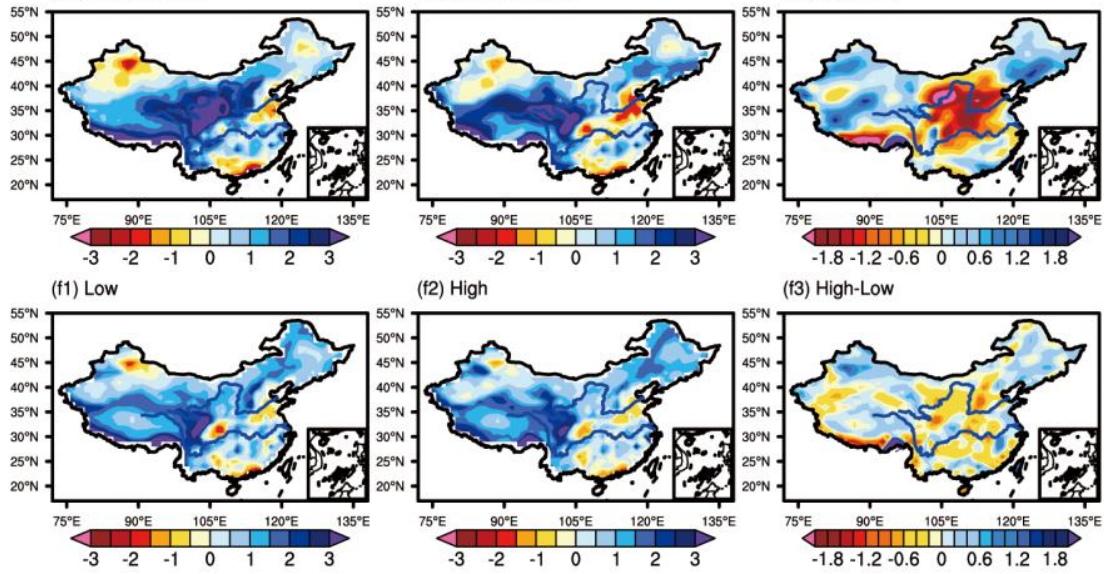

(f3) High-Low

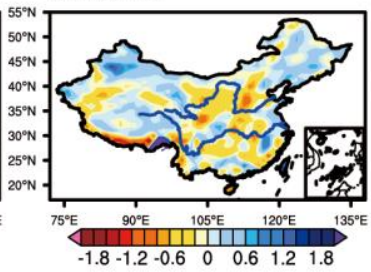

Figure 3. The spatial patterns of biases (departures from CN05.1) in SDII (unit: $\mathrm{mm} /$ day) for longterm mean (1995-2014) from low-resolution (first column) and high-resolution (second column) models, and differences between low-resolution and high-resolution models (third column). The last row shows multimodels with low-resolution ensemble means (f1) and multimodels with highresolution ensemble means (f2), respectively. 

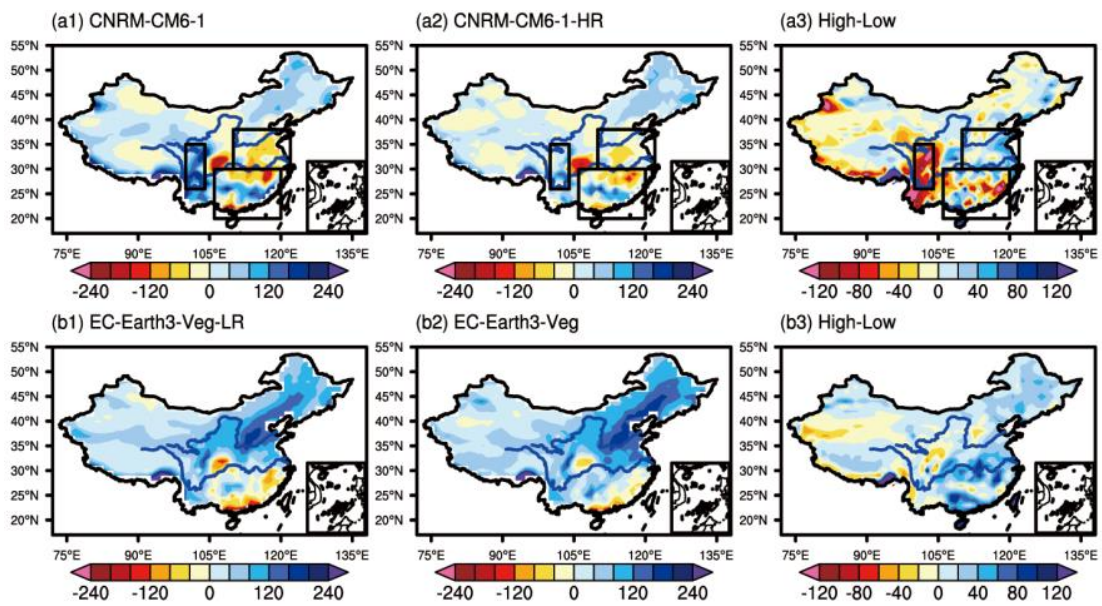

(b3) High-Low

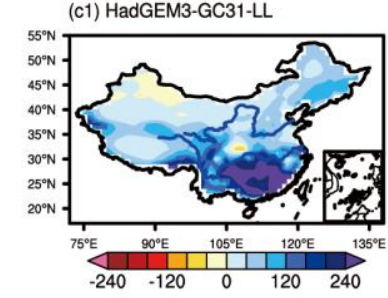

(c2) HadGEM3-GC31-MM
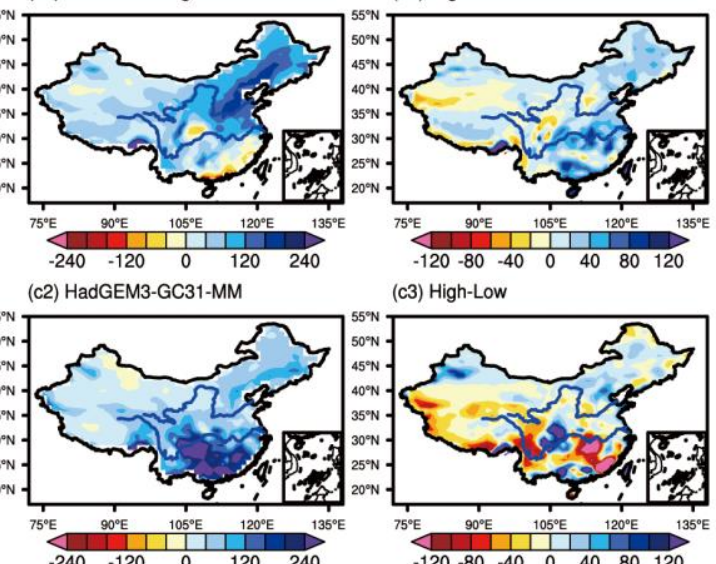

(c3) High-Low
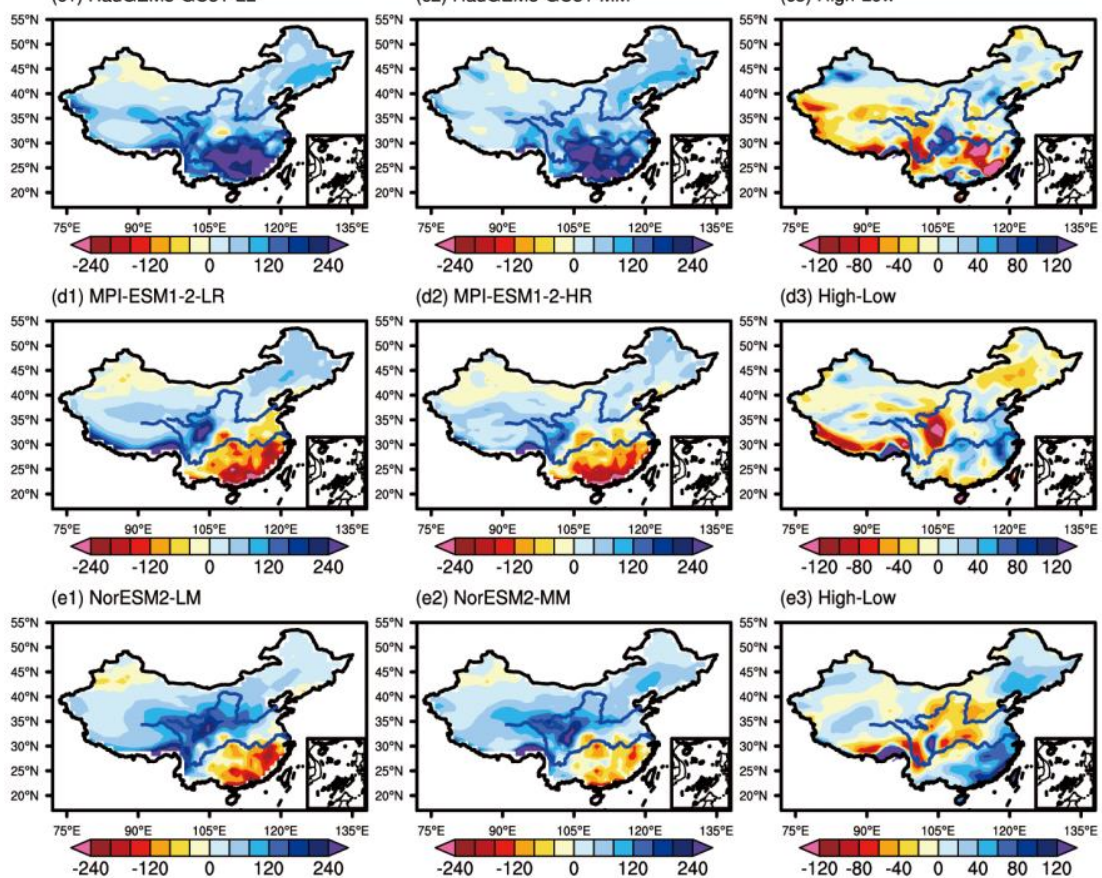

(e2) NorESM2-MM
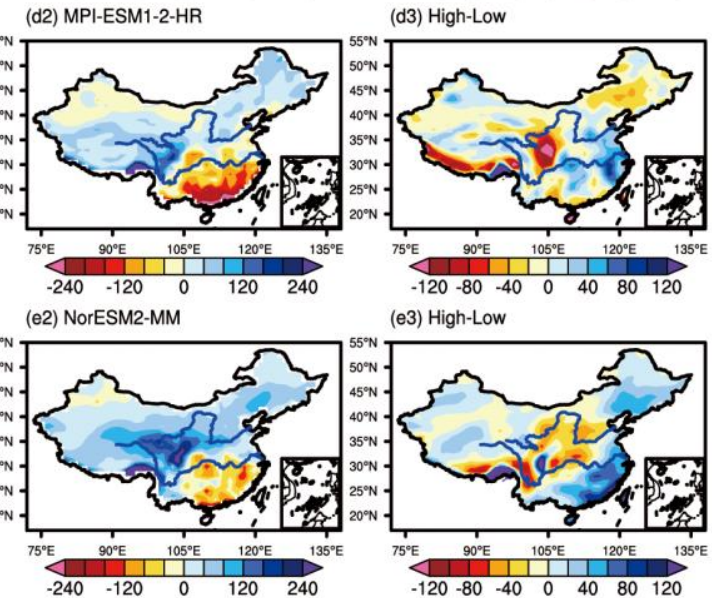

(e3) High-Low

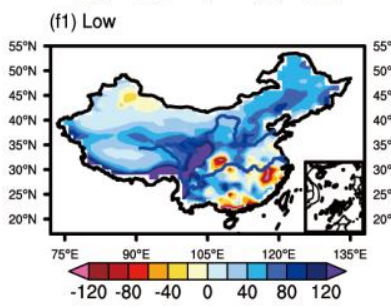

(f2) High
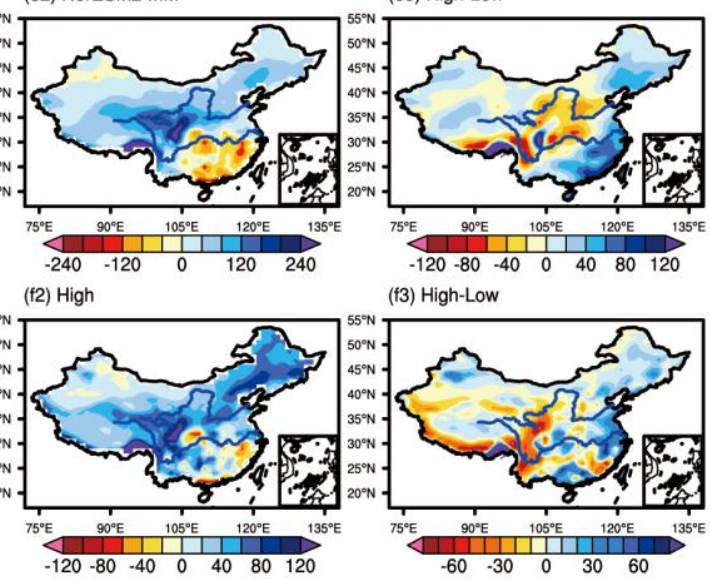
(†3) High-Low

Figure 4. The spatial patterns of biases (departures from CN05.1) in R95p (unit: mm) for long-term mean (1995-2014) from low-resolution (first column) and high-resolution (second column) models, and differences between low-resolution and high-resolution models (third column). The last row shows multimodels with low-resolution ensemble means (f1) and multimodels with high-resolution ensemble means (f2), respectively.

The spatial distribution of model biases in R20mm over China is shown in Figure 5. We found that all models with high resolution show a uniform reduction in biases over D1, D2, and D3. For example, the obvious reduction in RMSE is 33.3\% (2.0\%) in CNRM-CM6, $31.6 \%(56.4 \%)$ in HadGEM3, $15.6 \%$ (53.1\%) in NorESM2, and 18.1\% (29.8\%) in MME over D2 (D3). Figure 6 shows the spatial pattern of model biases in CDD over China. When compared with low resolution models, the biases with high-resolution models over D1, 
D2 and D3 are reduced to some extent. For example, the reduction in RMSE is $29.0 \%$ (43.5\%) in CNRM-CM6 and 20.0\% (21.8\%) in NorESM2 over D1 (D2). Furthermore, biases in the western part of Northwest China $\left(36-46^{\circ} \mathrm{N}, 75-100^{\circ} \mathrm{E}\right)$ are also lower in models with high resolutions, with the reduction of RMSE achieving 23.9\% in CNRM-CM6, 16.5\% in HadGEM3, and 11.0\% in MME. The better simulation of the CDD index could be associated with the simulation of the WD index (Figure 2). That is, the reduction in wet days may contribute to increased dry days.
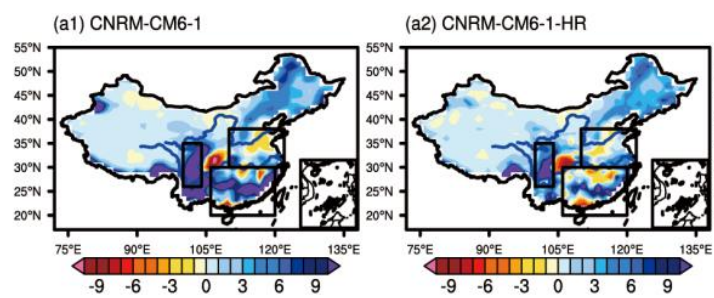

(a3) High-Low

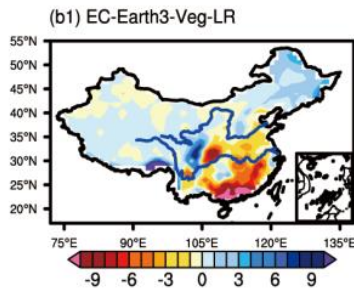

(b2) EC-Earth3-Veg
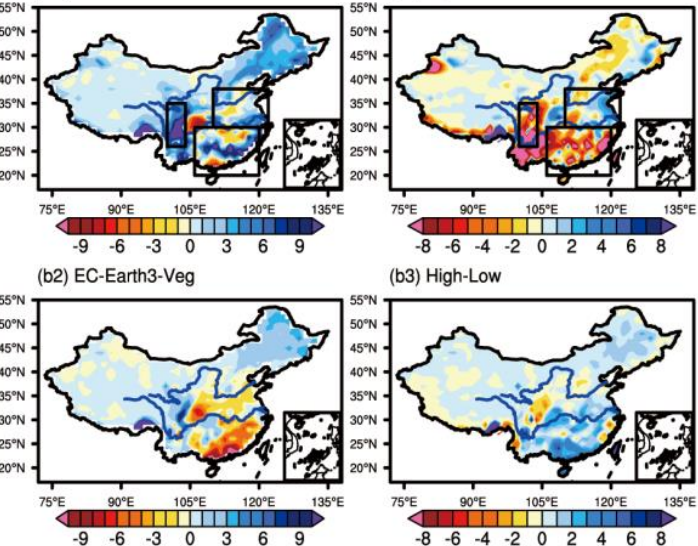
(b3) High-Low

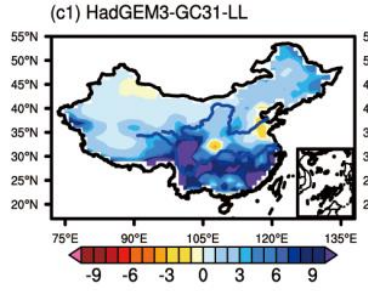
(c2) HadGEM3-GC31-MM
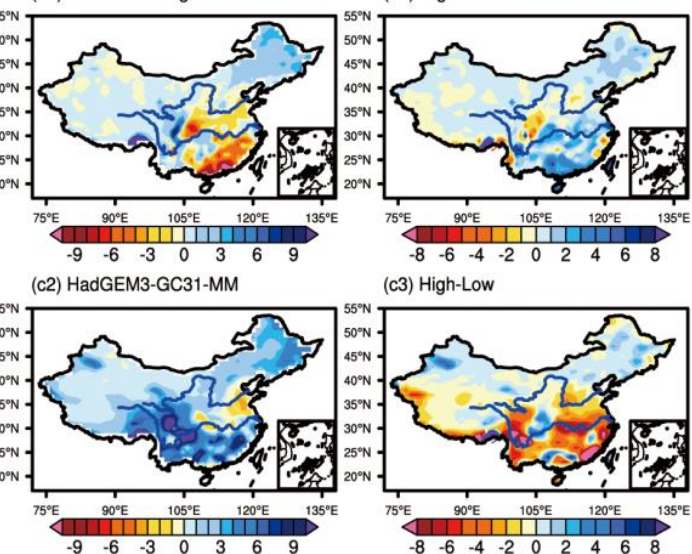
(c3) High-Low

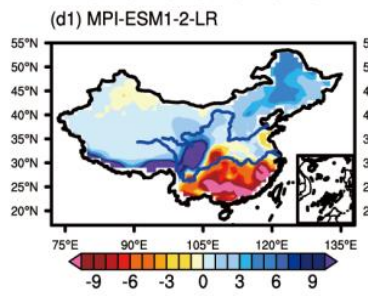

(d2) MPI-ESM1-2-HR

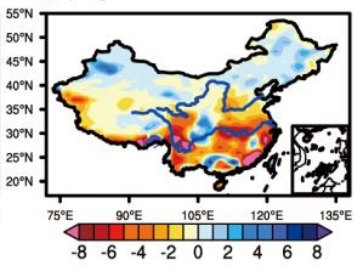
(d3) High-Low
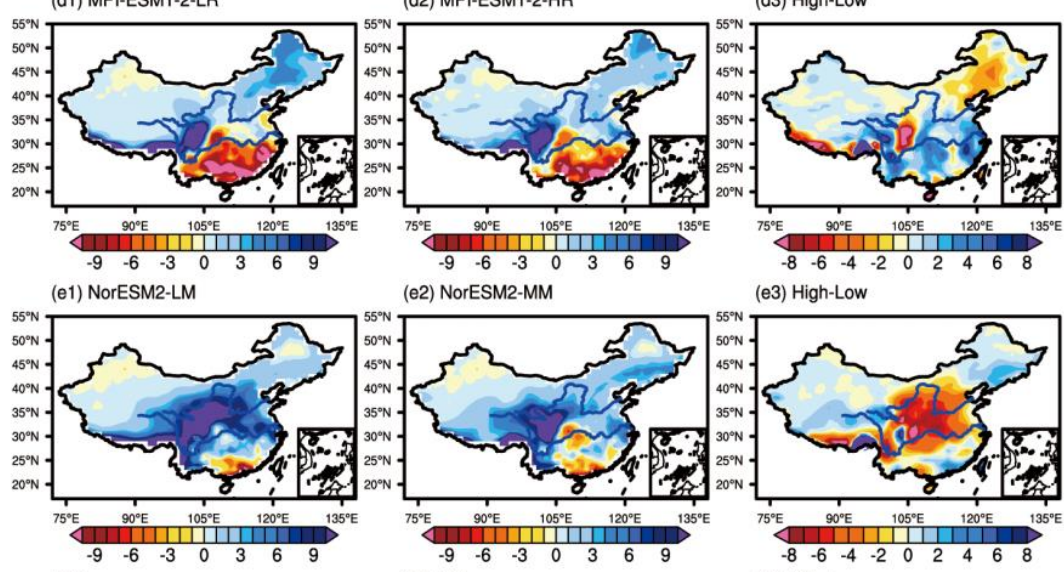

(e2) NorESM2-MM (e3) High-Low
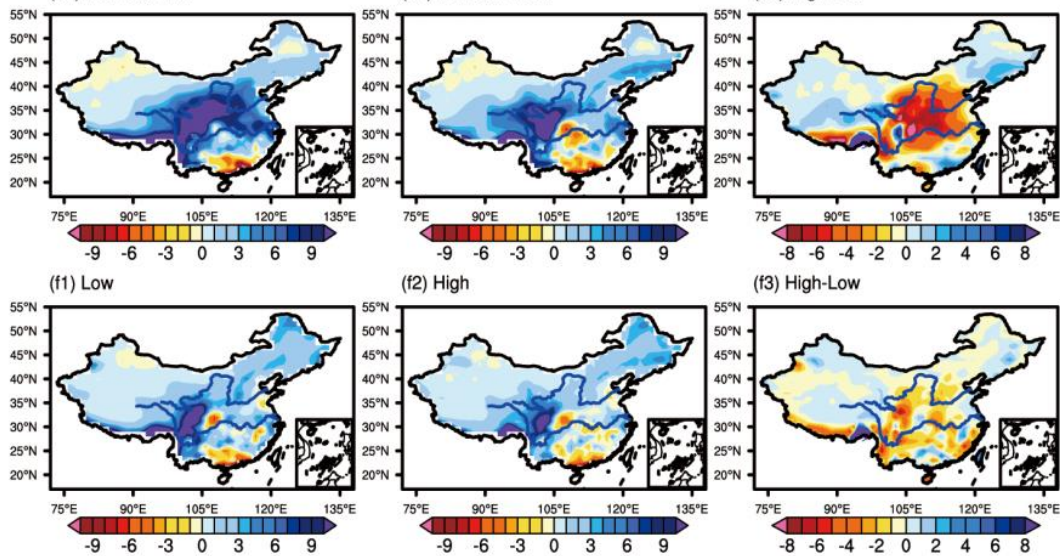
(f2) High (†3) High-Low
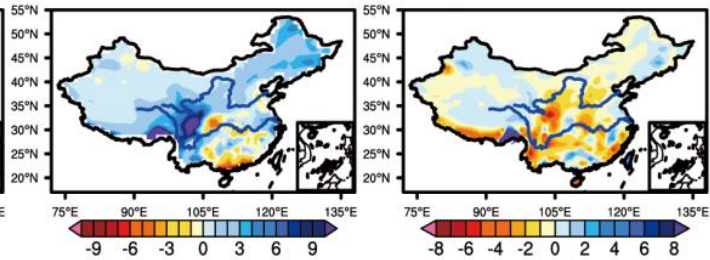

Figure 5. The spatial patterns of biases (departures from CN05.1) in R20mm (unit: days) for long-term mean (1995-2014) from low-resolution (first column) and high-resolution (second column) models, and differences between low-resolutions and high-resolutions models (third column). The last row shows multimodels with low-resolution ensemble means (f1) and multimodels with high-resolution ensemble means (f2), respectively. 

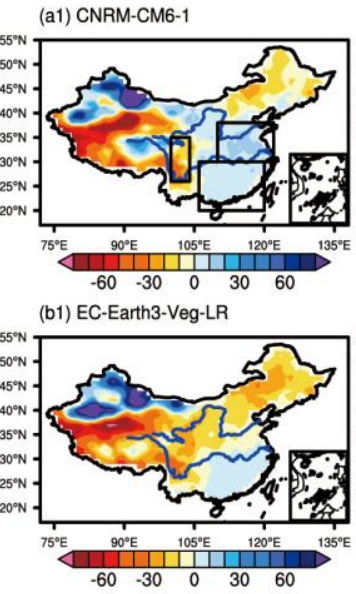

(c1) HadGEM3-GC31-LL

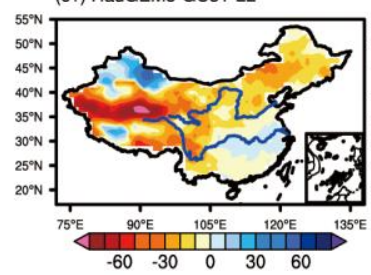

(d1) MPI-ESM1-2-LR

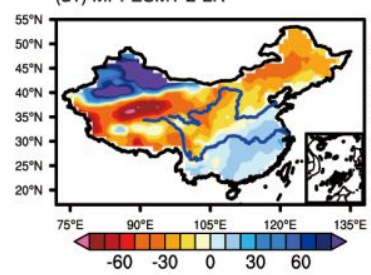

(e1) NorESM2-LM

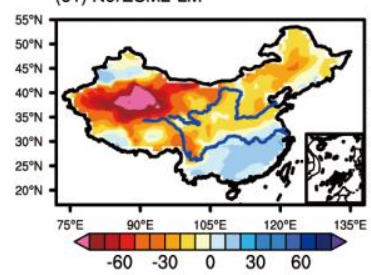

(f1) Low

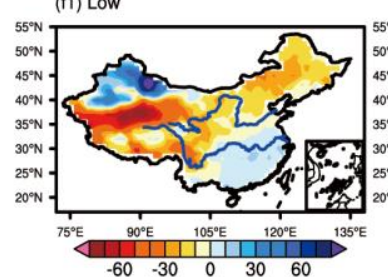

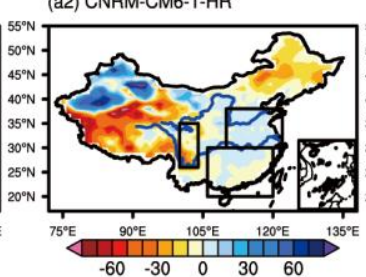

(b2) EC-Earth3-Veg

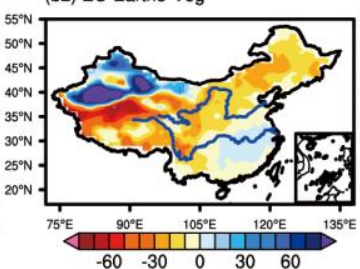

(c2) HadGEM3-GC31-MM

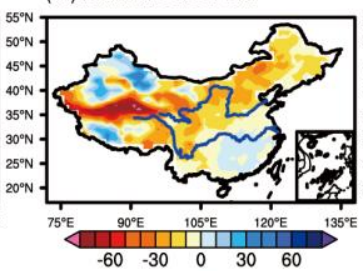

(d2) MPI-ESM1-2-HR

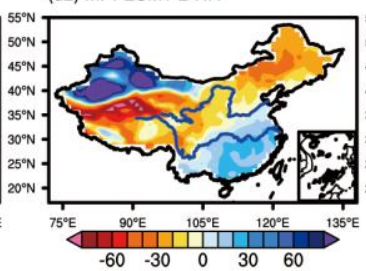

(e2) NorESM2-MM

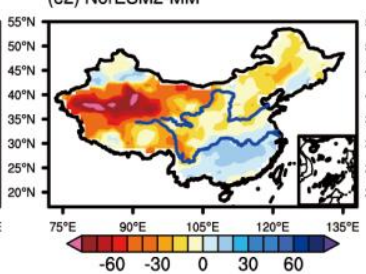

(f2) High

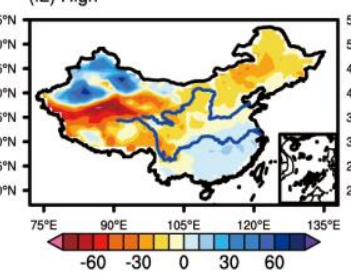

(a3) High-Low

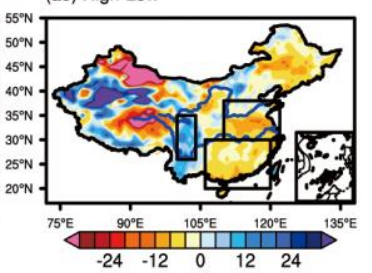

(b3) High-Low

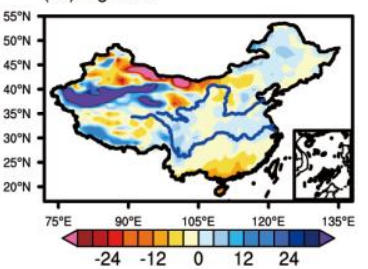

(c3) High-Low

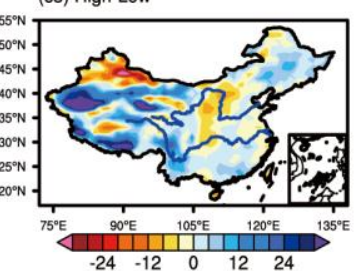

(d3) High-Low

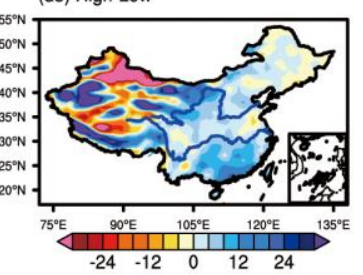

(e3) High-Low

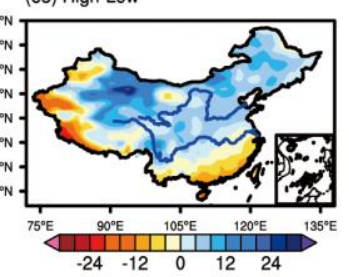

(f3) High-Low

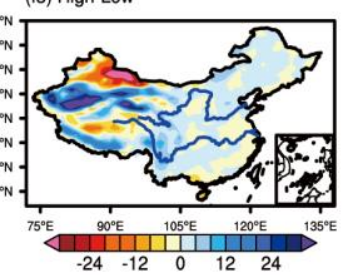

Figure 6. The spatial patterns of biases (departures from CN05.1) in CDD (unit: days) for long-term mean (1995-2014) from low-resolution (first column) and high-resolution (second column) models, and differences between low-resolution and high-resolution models (third column). The last row shows multimodels with low-resolution ensemble means (f1) and multimodels with high-resolution ensemble means (f2), respectively.

Evaluation of models using Taylor diagrams (Figure 7) for six extreme precipitation indices shows that most models in high resolution show improvements in simulating WD over China, compared with their counterparts in low resolution, such as the CNRM-CM6, EC-Earth3, and MPI-ESM1 models. Most models with improved resolutions show no obvious improvement in representing the features of R95p and in particular for R20mm over China. However, for the CDD index, all models with high resolutions show better performance compared with their counterparts with low resolutions. It is worth noting 
that models show a wide range of skill in reproducing the spatial distribution of CDD over China. That is, the inter-model distance is obviously large (Figure $7 \mathrm{f}$ ).
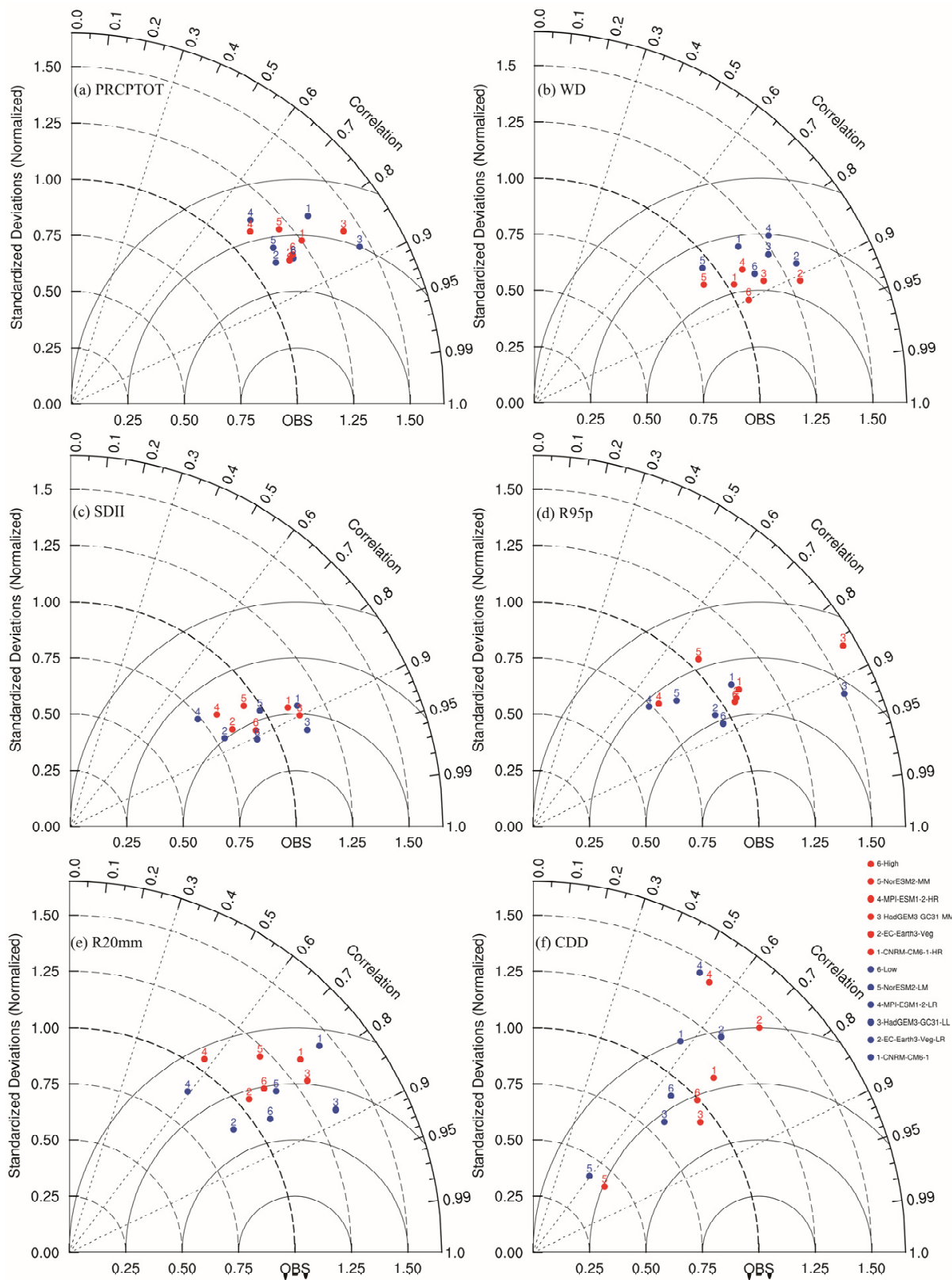

Figure 7. The Taylor diagram for three precipitation indices (PRCPTOT (a), WD (b), SDII (c), R95p (d), R20mm (e), and CDD (f)) over China from individual models with high and low resolutions, multimodels with low-resolution ensemble means, and multimodels with high-resolution ensemble means.

\subsection{Possible Reasons for the Improved Precipitation Extremes Simulation in High-Resolution Models}

Previous studies have reported that model resolutions might have non-negligible effect in simulations on the distribution of daily precipitation frequency [38]. Figure 8 shows the distributions of daily precipitation frequency as a function of daily precipitation intensity from 0 to $100 \mathrm{~mm}$ /day regionally averaged over D1, D2, and D3. Fewer weak precipitation events $(0 \mathrm{~mm} /$ day $-10 \mathrm{~mm} /$ day $)$ could be found in nearly all models with updated resolutions over D1 in comparison with their counterparts with low resolutions. Therefore, the decreased biases of precipitation over D1 are associated with fewer weak 
precipitation events. The so-called "drizzling too much" phenomenon presented by climate models in previous studies [39] is improved with updated model resolutions to some extent. For CNRM-CM6 and HadGEM3 (EC-Earth3 and NorESM2), these models with high resolutions capture decreasing (increasing) $10 \mathrm{~mm} /$ day- $-60 \mathrm{~mm} /$ day $(>30 \mathrm{~mm} /$ day) precipitation compared with their counterparts with low resolutions, which is associated with decreased (increased) precipitation over D2 (Figures 1 and 4). Comparing MME in lowresolution and high resolution versions simulates less $0 \mathrm{~mm} /$ day $-30 \mathrm{~mm} /$ day precipitation, thus causing the decreased precipitation over D2 (Figure 1). In addition, for HadGEM3 and NorESM2, high-resolution versions show decreased precipitation over D3 (Figures 1 and 4), which is also related to the simulated precipitation of less than $10 \mathrm{~mm} /$ day $-50 \mathrm{~mm} /$ day in these models in comparison with low resolutions.

Previous studies have reported that the vertical profile of the moisture content of the atmosphere $[40,41]$ plays an important role in the simulation of convective rainfall. Therefore, the vertical distribution of moisture with simulated extreme precipitation was studied. Figure 9 shows the structure of moisture with precipitation in summer over D2 from models and observations. The combination of ERA5 relative humidity with CN05.1 precipitation (CN05.1/ERA5) was seen as the observation. Extreme precipitation related to strong deep convection is more easily triggered when the lower atmosphere above the boundary layer experiences sufficient moistening and a deep layer of the air column is nearly saturated [40]. We noticed that all models with low resolutions show excessive moisture in the upper atmosphere $(500 \mathrm{hPa}-250 \mathrm{hPa})$ in comparison with high-resolution versions. The simulation of the vertical distribution of moisture in high-resolution versions is closer to the observation, in comparison with low-resolution versions, thus possibly contributing to the better performance in the simulation of extreme precipitation with high-resolution versions.

D1
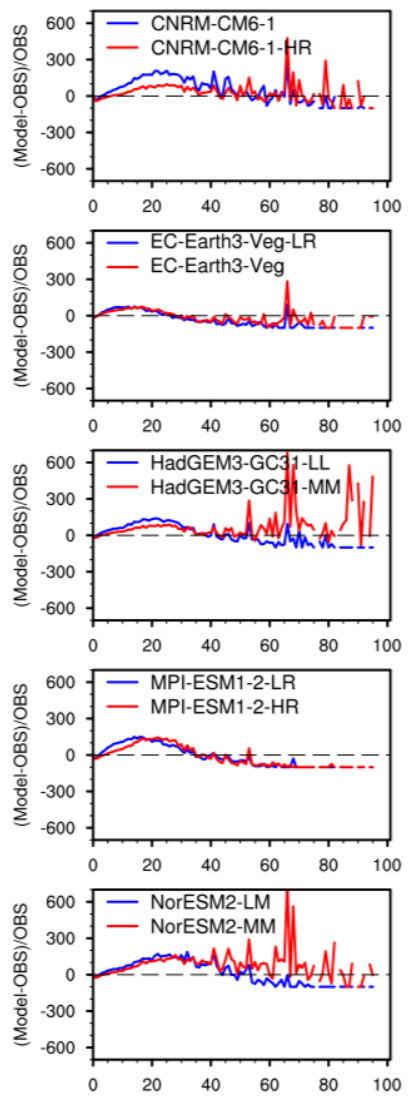

Figure 8. Cont.
D2
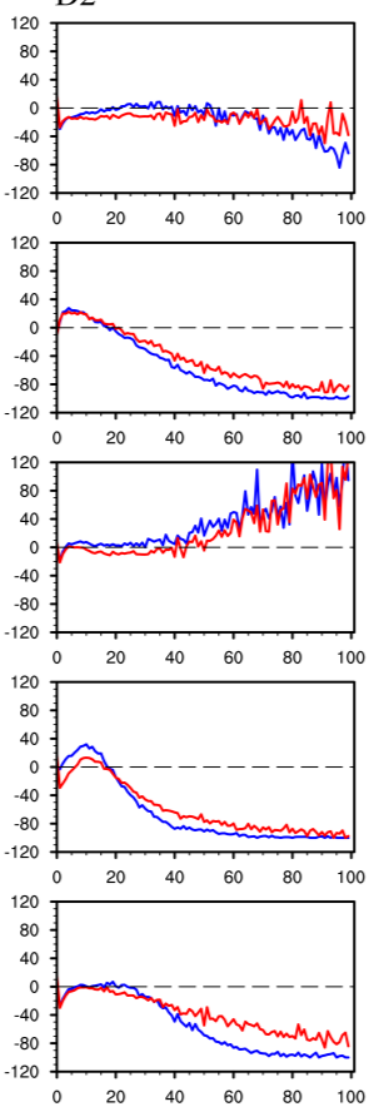
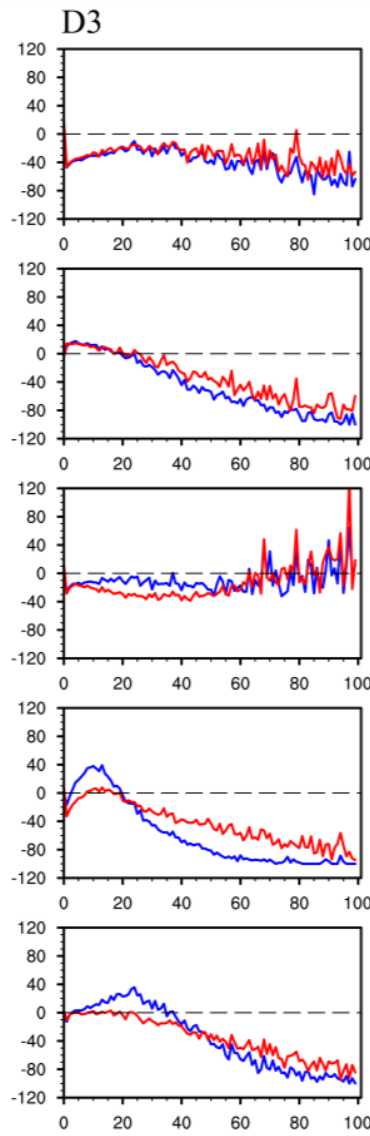

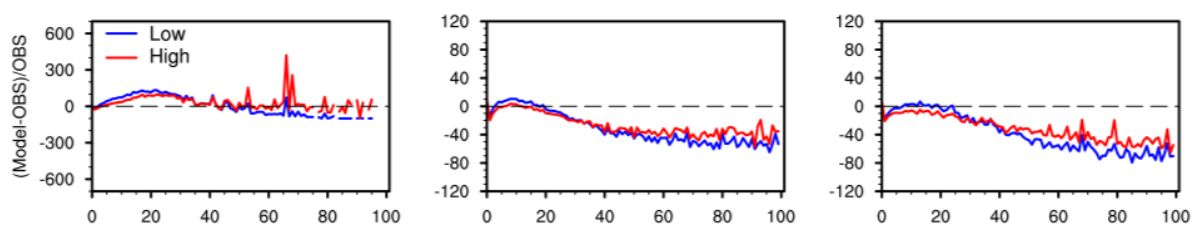

Figure 8. Relative bias curve of precipitation frequency distribution as a function of daily precipitation intensity (bin size $1 \mathrm{~mm}^{\text {day }}{ }^{-1}$ ) over three subregions from individual models with low and high resolutions, multimodels with low-resolution ensemble means, and multimodels with high-resolution ensemble means (left $y$-axis, units: \%). The unit of the $x$-axis is $\mathrm{mm} \mathrm{day}^{-1}$. Biases are shown as percentages relative to the observations. The first to third column corresponds to (D1), (D2), and (D3), respectively.
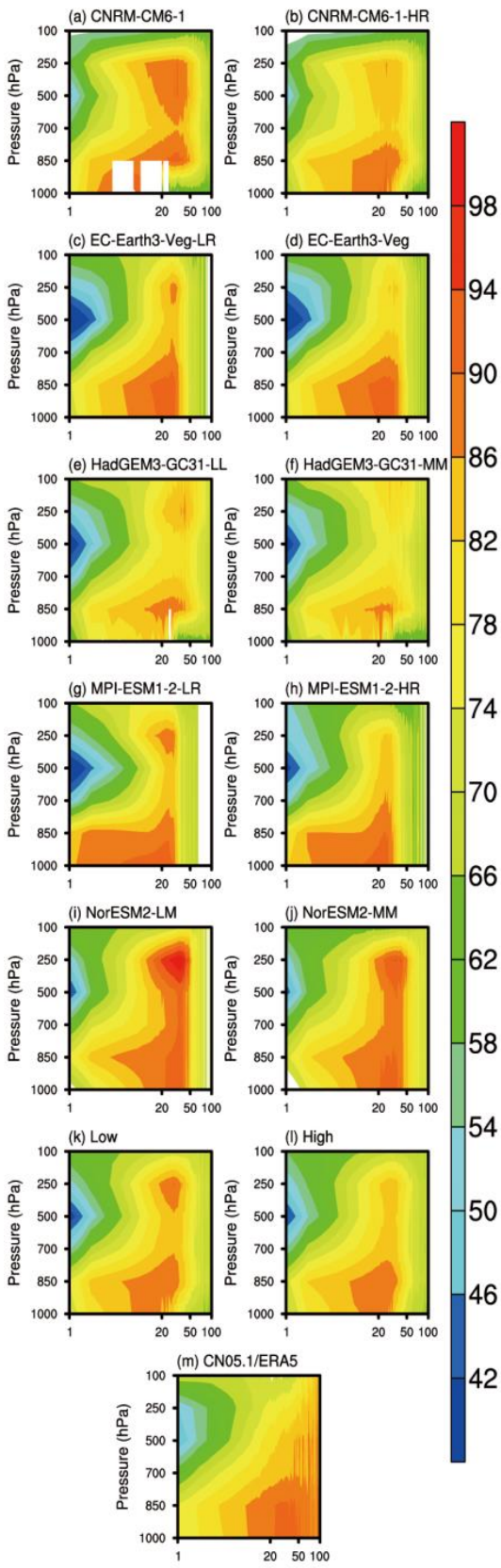

Figure 9. Composite vertical profiles of relative humidity (unit: \%) based on precipitation intensity in summer over D2 from individual models $(\mathbf{a}-\mathbf{j})$, multimodels with low-resolution ensemble means (k), multimodels with high-resolution ensemble means (1), and CN05.1/ERA5 (m). 


\section{Discussion}

This work provides a preliminary evaluation of precipitation extremes in terms of the effect of model resolution. Although consistent improvements in light rainfall can be found with updated resolutions, large model differences still exist in the five models. For example, the impact of higher resolutions on the simulation of R95p varies greatly in the five models. The above differences are possibly associated with the different reactions of some physical processes to the resolution. Thus, some key physical processes are also important for better simulation in high-resolution models.

The number of models used in this study is limited and model resolutions are not high enough. To fully investigate the impact of model resolution on the simulation of precipitation extremes, more models with higher resolutions from CMIP6 are required, and further assessment of the impact of model resolution in other ways is also needed.

\section{Conclusions}

Based on five CMIP6 models, each having a pair of high-resolution and low-resolution configurations, the difference between low-resolution models and high-resolution models in representing the spatial pattern of climatological precipitation extremes over China during 1995-2014 was compared. Generally, models in high resolution show better performance over China, especially over D1, D2, and D3. The decreased biases of total precipitation (PRCPTOT) over D1 were found in all models with updated resolutions, with the largest decease in RMSE being $48.4 \%$ in CNRM-CM6, which is associated with fewer weak precipitation events $(0 \mathrm{~mm} /$ day $-10 \mathrm{~mm} /$ day $)$. Models with updated resolutions also show smaller biases than their counterparts with low resolutions for the simulation of precipitation over D2. For instance, the RMSE is reduced by $29.9 \%$ in CNRM-CM6 for PRCPTOT index and 31.2\% in NorESM2 for extreme precipitation amount (R95p), respectively. These improvements could be attributed to better representation of the distribution of daily precipitation frequency. In addition, the vertical distribution of moisture content in models with updated resolutions is closer to the observation in comparison with models with low resolutions, thus showing better performance for extreme precipitation over D2.

Overall, our results indicate that models with improved resolution show an obvious advantage in the simulation of precipitation extremes, in particular for some regions with complex terrain. In addition, models with updated resolution also demonstrate an improvement in the simulation for light precipitation and heavy precipitation. To some extent, high-resolution models increase our confidence in precipitation extremes simulation. However, high-resolution simulation is very expensive, especially for global simulation. Therefore, higher demands are placed on the development of computers. In addition, some key physical processes are also crucial for simulation in extreme precipitation. Better physical parameterizations are also needed.

Supplementary Materials: The following are available online at https:/ /www.mdpi.com/article/10 .3390/su14010025/s1, Figure S1: Spatial distribution of R95p (unit: mm) for long-term mean (19952014) from individual models $(\mathrm{a}-\mathrm{j})$ and observation (k), Figure S2: Spatial distribution of R20mm (unit: days) for long-term mean (1995-2014) from individual models (a-j) and observation (k), Figure S3: Spatial distribution of PRCPTOT (unit: $\mathrm{mm}$ ) for long-term mean (1995-2014) from individual models $(\mathrm{a}-\mathrm{j})$ and observation $(\mathrm{k})$. Figure S4: Spatial distribution of CDD (unit: days) for long-term mean (1995-2014) from individual models (a-j) and observation $(k)$.

Author Contributions: Conceptualization, supervision, and writing-review and editing, Y.G.; writing-original draft preparation and visualization, N.L. All authors have read and agreed to the published version of the manuscript.

Funding: This study is jointly supported by the National Key Research and Development Program of China, grant numbers 2020YFA0608201 and 2018YFC1509002.

Institutional Review Board Statement: Not applicable.

Informed Consent Statement: Not applicable. 
Data Availability Statement: Not applicable.

Acknowledgments: We thank the three anonymous reviewers for their helpful comments and suggestions. We also appreciate Rui He for helpful advice for our manuscript.

Conflicts of Interest: The authors declare no conflict of interest.

\section{References}

1. Duliè, V.R.; Zhang, Y.; Salathé, E.P. Extreme precipitation and temperature over the U.S. Pacific Northwest: A comparison between observations, reanalysis data, and regional models. J. Clim. 2011, 24, 1950-1964. [CrossRef]

2. Gao, Z.; Zhu, J.; Guo, Y.; Luo, N.; Fu, Y.; Wang, T. Impact of Land Surface Processes on a Record-Breaking Rainfall Event on May 06-07, 2017, in Guangzhou, China. J. Geophys. Res. Atmos. 2021, 126, e2020JD032997. [CrossRef]

3. Zhou, Z.Q.; Xie, S.P.; Zhang, R. Historic Yangtze flooding of 2020 tied to extreme Indian Ocean conditions. Proc. Natl. Acad. Sci. USA 2021, 118, e2022255118. [CrossRef] [PubMed]

4. Su, A.; Lü, X.; Cui, L.; Li, Z.; Xi, L.; Li, H. The Basic Observational Analysis of “7.20" Extreme Rainstorm in Zhengzhou. Torrential Rain Disasters 2021, 40, 445-454.

5. Duffy, P.B.; Govindasamy, B.; Lorio, J.P.; Milovich, J.; Sperber, K.R.; Taylor, K.E.; Wehner, M.F.; Thompson, S.L. High-resolution simulations of global climate, Part 1: Present climate. Clim. Dyn. 2003, 21, 371-390. [CrossRef]

6. Greenberg, D.A.; Dupont, F.; Lyard, F.H.; Lynch, D.R.; Werner, F.E. Resolution issues in numerical models of oceanic and coastal circulation. Cont. Shelf Res. 2007, 27, 1317-1343. [CrossRef]

7. Knutson, T.R.; McBride, J.L.; Chan, J.; Emanuel, K.; Holland, G.; Landsea, C.; Held, I.; Kossin, J.P.; Srivastava, A.K.; Sugi, M. Tropical cyclones and climate change. Nat. Geosci. 2010, 3, 157-163. [CrossRef]

8. Vidale, P.L.; Hodges, K.; Vannière, B.; Davini, P.; Roberts, M.J.; Strommen, K.; Weisheimer, A.; Plesca, E.; Corti, S. Impact of stochastic physics and model resolution on the simulation of tropical cyclones in climate GCMs. J. Clim. 2021, 34, 4315-4341. [CrossRef]

9. Guilyardi, E.; Gualdi, S.; Slingo, J.; Navarra, A.; Delecluse, P.; Cole, J.; Madec, G.; Roberts, M.; Latif, M.; Terray, L. Representing El Niño in coupled ocean-atmosphere GCMs: The dominant role of the atmospheric component. J. Clim. 2004, 17, 4623-4629. [CrossRef]

10. Rauscher, S.A.; Coppola, E.; Piani, C.; Giorgi, F. Resolution effects on regional climate model simulations of seasonal precipitation over Europe. Clim. Dyn. 2010, 35, 685-711. [CrossRef]

11. Huang, D.Q.; Zhu, J.; Zhang, Y.C.; Huang, A.N. Uncertainties on the simulated summer precipitation over Eastern China from the CMIP5 models. J. Geophys. Res. Atmos. 2013, 118, 9035-9047. [CrossRef]

12. Zhang, L.; Wu, P.; Zhou, T.; Roberts, M.J.; Schiemann, R. Added value of high resolution models in simulating global precipitation characteristics. Atmos. Sci. Lett. 2016, 17, 646-657. [CrossRef]

13. He, S.; Yang, J.; Bao, Q.; Wang, L.; Wang, B. Fidelity of the observational/reanalysis datasets and global climate models in representation of extreme precipitation in East China. J. Clim. 2019, 32, 195-212. [CrossRef]

14. Demory, M.E.; Vidale, P.L.; Roberts, M.J.; Berrisford, P.; Strachan, J.; Schiemann, R.; Mizielinski, M.S. The role of horizontal resolution in simulating drivers of the global hydrological cycle. Clim. Dyn. 2014, 42, 2201-2225. [CrossRef]

15. Prein, A.F.; Langhans, W.; Fosser, G.; Ferrone, A.; Ban, N.; Goergen, K.; Keller, M.; Tölle, M.; Gutjahr, O.; Feser, F.; et al. A review on regional convection-permitting climate modeling: Demonstrations, prospects, and challenges. Rev. Geophys. 2015, 53, 323-361. [CrossRef] [PubMed]

16. Lin, L.; Gettelman, A.; Xu, Y.; Wu, C.; Wang, Z.; Rosenbloom, N.; Bates, S.C.; Dong, W. CAM6 simulation of mean and extreme precipitation over Asia: Sensitivity to upgraded physical parameterizations and higher horizontal resolution. Geosci. Model Dev. 2019, 12, 3773-3793. [CrossRef]

17. Eyring, V.; Bony, S.; Meehl, G.A.; Ronald, S.; Oceanic, N. Overview of the Coupled Model Intercomparison Project Phase 6 (CMIP6) experimental design and organisation. Geosci. Model Dev. Discuss. 2015, 8, 10539-10583. [CrossRef]

18. Xin, X.; Wu, T.; Zhang, J.; Yao, J.; Fang, Y. Comparison of CMIP6 and CMIP5 simulations of precipitation in China and the East Asian summer monsoon. Int. J. Climatol. 2020, 40, 6423-6440. [CrossRef] 
19. Chen, H.; Sun, J.; Lin, W.; Xu, H. Comparison of CMIP6 and CMIP5 models in simulating climate extremes. Sci. Bull. 2020, 65, 1415-1418. [CrossRef]

20. Zhu, X.; Ji, Z.; Wen, X.; Lee, S.Y.; Wei, Z.; Zheng, Z.; Dong, W. Historical and projected climate change over three major river basins in China from Fifth and Sixth Coupled Model Intercomparison Project models. Int. J. Climatol. 2021, 1-19. [CrossRef]

21. Zhu, Y.Y.; Yang, S. Evaluation of CMIP6 for historical temperature and precipitation over the Tibetan Plateau and its comparison with CMIP5. Adv. Clim. Chang. Res. 2020, 11, 239-251. [CrossRef]

22. Dong, T.; Dong, W. Evaluation of extreme precipitation over Asia in CMIP6 models. Clim. Dyn. 2021, 57, 1751-1769. [CrossRef]

23. Luo, N.; Guo, Y.; Chou, J.; Gao, Z. Added value of CMIP6 models over CMIP5 models in simulating the climatological precipitation extremes in. Int. J. Climatol. 2021, 1-17. [CrossRef]

24. Jiang, D.; Hu, D.; Tian, Z.; Lang, X. Differences between CMIP6 and CMIP5 Models in Simulating Climate over China and the East Asian Monsoon. Adv. Atmos. Sci. 2020, 37, 1102-1118. [CrossRef]

25. Hu, Y.-Y.; Xu, Y.; Li, J.-J.; Han, Z.-Y. Evaluation on the performance of CMIP6 global climate models with different horizontal resolution in simulating the precipitation over China. Clim. Chang. Res. 2021, 17, 730-743.

26. Wu, J.; Gao, X.J. A gridded daily observation dataset over China region and comparison with the other datasets. Acta Geophys. Sin. 2013, 56, 1102-1111. [CrossRef]

27. Yin, H.; Donat, M.G.; Alexander, L.V.; Sun, Y. Multi-dataset comparison of gridded observed temperature and precipitation extremes over China. Int. J. Climatol. 2015, 35, 2809-2827. [CrossRef]

28. Zhou, B.; Xu, Y.; Wu, J.; Dong, S.; Shi, Y. Changes in temperature and precipitation extreme indices over China: Analysis of a high-resolution grid dataset. Int. J. Climatol. 2016, 36, 1051-1066. [CrossRef]

29. Hersbach, H.; Bell, B.; Berrisford, P.; Hirahara, S.; Horányi, A.; Muñoz-Sabater, J.; Nicolas, J.; Peubey, C.; Radu, R.; Schepers, D.; et al. The ERA5 Global Reanalysis. Q. J. R. Meteorol. Soc. 2020, 146, 1999-2049. [CrossRef]

30. Xu, C.; Luo, Y.; Xu, Y. Projected changes of precipitation extremes in river basins over China. Quat. Int. 2011, 244, 149-158. [CrossRef]

31. Zhou, B.; Wen, Q.H.; Xu, Y.; Song, L.; Zhang, X. Projected changes in temperature and precipitation extremes in China by the CMIP5 multimodel ensembles. J. Clim. 2014, 27, 6591-6611. [CrossRef]

32. Taylor, K.E. Summarizing multiple aspects of model performance in a single diagram. J. Geophys. Res. Atmos. 2001, 106, 7183-7192. [CrossRef]

33. Gao, X.; Shi, Y.; Song, R.; Giorgi, F.; Wang, Y.; Zhang, D. Reduction of future monsoon precipitation over China: Comparison between a high resolution RCM simulation and the driving GCM. Meteorol. Atmos. Phys. 2008, 100, 73-86. [CrossRef]

34. Zou, L.; Zhou, T. Near future (2016-40) summer precipitation changes over China as projected by a regional climate model (RCM) under the RCP8.5 emissions scenario: Comparison between RCM downscaling and the driving GCM. Adv. Atmos. Sci. 2013, 30, 806-818. [CrossRef]

35. Feng, L.; Zhou, T.; Wu, B.; Li, T.; Luo, J.J. Projection of future precipitation change over China with a high-resolution global atmospheric model. Adv. Atmos. Sci. 2011, 28, 464-476. [CrossRef]

36. Bao, J.; Feng, J.; Wang, Y. Dynamical downscaling simulation and future projection of precipitation over China. J. Geophys. Res. Atmos. 2015, 120, 8227-8243. [CrossRef]

37. Wang, H.J.; Sun, J.Q.; Chen, H.P.; Zhu, Y.L.; Zhang, Y.; Jiang, D.B.; Lang, X.M.; Fan, K.; Yu, E.T.; Yang, S. Extreme climate in China: Facts, simulation and projection. Meteorol. Z. 2012, 21 , 279-304. [CrossRef]

38. Ganai, M.; Krishna, R.P.M.; Mukhopadhyay, P.; Mahakur, M. The impact of revised simplified Arakawa-Schubert scheme on the simulation of mean and diurnal variability associated with active and break phases of Indian summer monsoon using CFSv2. J. Geophys. Res. 2016, 121, 9301-9323. [CrossRef]

39. Stephens, G.L.; L'Ecuyer, T.; Forbes, R.; Gettlemen, A.; Golaz, J.C.; Bodas-Salcedo, A.; Suzuki, K.; Gabriel, P.; Haynes, J. Dreary state of precipitation in global models. J. Geophys. Res. Atmos. 2010, 115, 1-14. [CrossRef]

40. Kim, D.; Xavier, P.; Maloney, E.; Wheeler, M.; Waliser, D.; Sperber, K.; Hendon, H.; Zhang, C.; Neale, R.; Hwang, Y.T.; et al. Process-oriented MJO simulation diagnostic: Moisture sensitivity of simulated convection. J. Clim. 2014, 27, 5379-5395. [CrossRef] 
41. Holloway, C.E.; Neelin, D.J. Moisture vertical structure, column water vapor, and tropical deep convection. J. Atmos. Sci. 2009, 66, 1665-1683. [CrossRef] 